Available online at www.sciencedirect.com

\title{
Solution Structure, Dynamics, and Hydrodynamics of the Calcium-bound Cross-reactive Birch Pollen Allergen Bet v 4 Reveal a Canonical Monomeric Two EF-Hand Assembly with a Regulatory Function
}

\author{
Philipp Neudecker ${ }^{1 *}$, Jörg Nerkamp1, Anke Eisenmann ${ }^{1}$ \\ Amanda Nourse ${ }^{2}$, Thomas Lauber ${ }^{1}$, Kristian Schweimer ${ }^{1}$ \\ Katrin Lehmann ${ }^{1}$, Stephan Schwarzinger ${ }^{1}$, Fátima Ferreira ${ }^{3}$ \\ and Paul Rösch ${ }^{1 *}$
}

${ }^{1}$ Lehrstuhl für Biopolymere Universität Bayreuth, D-95440 Bayreuth, Germany

${ }^{2}$ Institute for Molecular Bioscience and Australian Research Council Special Research Centre for Functional and Applied Genomics University of Queensland Brisbane, Qld 4072, Australia

${ }^{3}$ Institut für Genetik und Allgemeine Biologie Universität Salzburg Hellbrunnerstraße 34, A-5020 Salzburg, Austria
Birch pollinosis is one of the prevailing allergic diseases. In all, 5-20\% of birch pollinotics mount IgE antibodies against the minor birch pollen allergen Bet $\mathrm{v} 4$, a $\mathrm{Ca}^{2+}$-binding polcalcin. Due to IgE cross-reactivity among the polcalcins these patients are polysensitized to various plant pollens. Determination of the high-resolution structure of holo Bet $\mathrm{v} 4$ by heteronuclear NMR spectroscopy reveals a canonical two EF-hand assembly in the open conformation with interhelical angles closely resembling holo calmodulin. The polcalcin-specific amphipathic $\mathrm{COOH}$-terminal $\alpha$-helix covers only a part of the hydrophobic groove on the molecular surface. Unlike the polcalcin Phl p 7 from timothy grass, which was recently shown to form a domain-swapped dimer, the hydrodynamic parameters from NMR relaxation, NMR translational diffusion, and analytical ultracentrifugation indicate that both apo and holo Bet $\mathrm{v} 4$ are predominantly monomeric, raising the question of the physiological and immunological significance of the dimeric form of these polcalcins, whose physiological function is still unknown. The reduced helicity and heat stability in the CD spectra, the poor chemical shift dispersion of the NMR spectra, and the slightly increased hydrodynamic radius of apo Bet v 4 indicate a reversible structural transition upon $\mathrm{Ca}^{2+}$ binding, which explains the reduced IgE binding capacity of apo Bet $v$ 4. The remarkable structural similarity of holo Bet $\mathrm{v} 4$ and holo Phl p 7 in spite of different oligomerization states explains the IgE cross-reactivity and indicates that canonical monomers and domain-swapped dimers may be of similar allergenicity. Together with the close structural homology to calmodulin and the hydrophobic ligand binding groove this transition suggests a regulatory function for Bet $\mathrm{v} 4$.

(C) 2004 Elsevier Ltd. All rights reserved.

Keywords: birch pollen allergen; EF-hand; heteronuclear NMR; polcalcin; solution structure heteronuclear single quantum coherence; IgE, immunoglobulin E; IPAP, in-phase/anti-phase; IPTG, isopropyl- $\beta$-Dthiogalactopyranoside; IUIS, International Union of Immunological Societies; NIH, National Institutes of Health; NOE, nuclear Overhauser effect; NOESY, nuclear Overhauser effect spectroscopy; PDB, Protein Data Bank; PG-SLED, pulse gradient stimulated echo longitudinal encode-decode; RMSD, root mean square deviation; RSDM, reduced spectral density mapping; TOCSY, total correlation spectroscopy.

E-mail addresses of the corresponding authors: philipp.neudecker@uni-bayreuth.de; paul.roesch@uni-bayreuth.de 


\section{Introduction}

Birch pollinosis is one of the prevailing allergic diseases in regions with birch trees, such as Northern and Central Europe and Northern America, and causes clinical syndromes like hay fever and asthma. The symptoms of this type I allergy are caused by an immune response, which is triggered when two receptor-bound immunoglobulin $\mathrm{E}(\mathrm{IgE})$ antibodies on the surface of a mast cell or basophil are cross-linked by simultaneous binding of an otherwise harmless antigen, the so-called allergen. The $17.4 \mathrm{kDa}$ major birch (Betula verrucosa) pollen allergen Bet $\mathrm{v} 1$ is responsible for IgE binding in more than $95 \%$ of birch pollen allergic patients, ${ }^{2}$ and due to cross-reaction of Bet $\mathrm{v} 1$ specific $\operatorname{IgE}$ antibodies with food allergens sharing a virtually identical tertiary structure with Bet $\mathrm{v} 1^{3-8}$ up to $70 \%$ of birch pollinotic patients also show hypersensitivity to fresh fruit or vegetables. ${ }^{9}$ In addition to Bet $\mathrm{v} 1$, six minor birch pollen allergens have been identified so far. ${ }^{9}$ Between $5 \%$ and $20 \%$ of birch pollinotics mount IgE antibodies against the $9.4 \mathrm{kDa}$ minor birch pollen allergen Bet $\mathrm{v} 4$, an acidic two EF-hand $\mathrm{Ca}^{2+}$-binding polcalcin. ${ }^{10,11} \mathrm{~A}$ series of allergenic polcalcins have been reported in the literature, namely Aln $g$ from alder (Alnus glutinosa), ${ }^{12}$ Ole e 3 from olive (Olea europaea), ${ }^{13,14}$ Syr v 3 from lilac (Syringa vulgaris; Ledesma et al., unpublished), Bra $\mathrm{n} 1$ or BPC1 and Bra $\mathrm{n} 2$ from oilseed rape (Brassica napus) as well as Bra $\mathrm{r} 1$ and Bra $\mathrm{r} 2$ from turnip rape (Brassica rapa), ${ }^{15-18} \mathrm{Phl} \mathrm{p} 7$ from timothy grass (Phleum pratense), ${ }^{19}$ and Cyn $\mathrm{d}$ 7 from Bermuda grass (Cynodon dactylon). ${ }^{20,21}$ Aln g 4, Syr v 3, Bra n 1 or BPC1, Bra n 2, Bra r 1, Bra r 2 and Phl p 7 as well as the polcalcin APC1 from mouse-ear cress (Arabidopsis thaliana), ${ }^{18}$ however, have not been included in the official allergen list of the International Union of Immunological Societies (IUIS) yet and the allergen designations Bra $\mathrm{n} 1$ and Bra r 2 even conflict with two unrelated allergens. ${ }^{22}$ These polcalcins share more than $65 \%$ sequence identity with Bet v 4 (Figure 1) and due to their widespread distribution over the plant kingdom and their high IgE cross-reactivity ${ }^{10-13,17,19-21}$ they might constitute so-called panallergens. ${ }^{23}$ The polcalcins, whose physiological function is still unknown, are specifically expressed in anthers and pollen ${ }^{10,14,15,17-21,24,25}$ and therefore no IgE cross-reactive food allergens have been described.

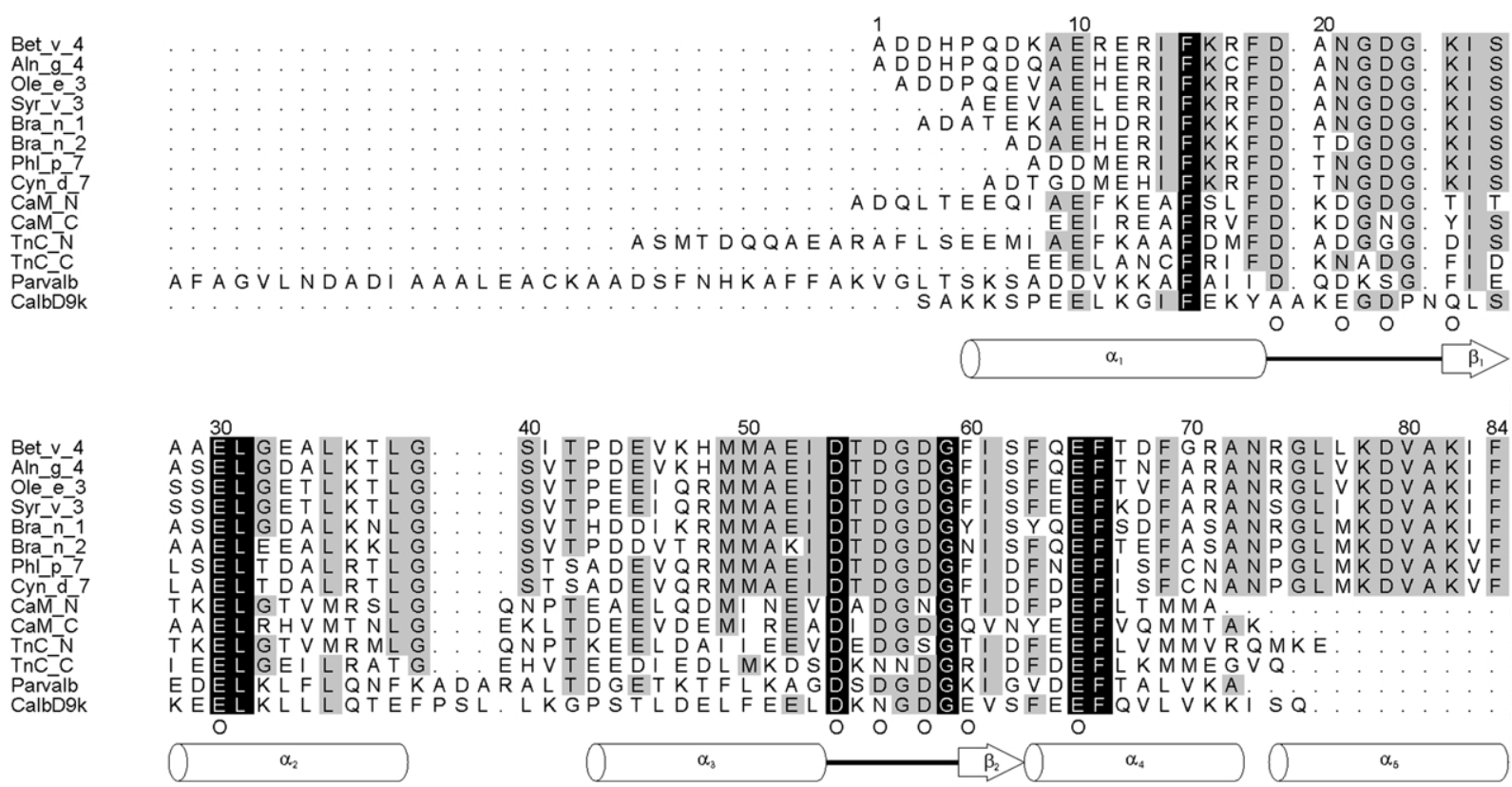

Figure 1. Structure-based sequence alignment with Bet v 4 of Aln g 4 (89.3\% sequence identity to Bet v 4), Ole e 3 $(79.5 \%)$, Syr v $3(77.5 \%)$, Bra n $1(74.4 \%)$, Bra n $2(73.2 \%)$, Phl p $7(68.8 \%)$, Cyn d $7(68.4 \%)$, the $\mathrm{NH}_{2}$-terminal $(36.6 \%)$ as well as the $\mathrm{COOH}$-terminal (41.5\%) domain of calmodulin from Homo sapiens, the $\mathrm{NH}_{2}$-terminal $(35.5 \%)$ as well as the $\mathrm{COOH}$-terminal (34.3\%) domain of troponin C from Gallus gallus, parvalbumin from Cyprinus carpio (27.8\%), and calbindin $\mathrm{D}_{9 \mathrm{k}}$ from Bos taurus (27.4\%). Bra r 1 and Bra r 2 are identical with Bra $\mathrm{n} 1$ and Bra $\mathrm{n}$ 2, respectively. The initiating methionine of the polcalcins, which is posttranslationally cleaved off during recombinant production in $E$. coli $i^{10,14}$ and therefore not visible in the NMR spectra of holo Bet $v 4$, was omitted. The sequence positions above the sequences correspond to Bet v 4. Gaps in the alignment are indicated by dots. Residues conserved in at least eight of the 14 domains are highlighted by gray boxes, residues conserved in all 14 domains by black boxes. Residues involved in the $\mathrm{Ca}^{2+}$ ligation are indicated by an $\mathrm{O}$ below the alignment. The secondary structure elements including the Ca ${ }^{2+}$ binding loops of the two EF-hands of holo Bet $\mathrm{v} 4$ are also shown below the alignment and are identical with those of holo Phl p 7 except that the $\mathrm{NH}_{2}$-terminal helix of holo Phl p 7 starts from Asp2 corresponding to Ala9 of Bet v 4. Troponin $\mathrm{C}$ contains an additional $\alpha$-helix at the $\mathrm{NH}_{2}$ terminus, parvalbumin even an additional non-functional EFhand. The $\mathrm{Ca}^{2+}$ binding loop of the first EF-hand of calbindin $\mathrm{D}_{9 \mathrm{k}}$ contains two additional residues and primarily uses backbone carbonyl oxygen atoms for $\mathrm{Ca}^{2+}$ ligation. The alignment was performed manually and formatted using ALSCRIPT. ${ }^{91}$ 
Polcalcin accumulation at the tip of growing pollen tubes $^{18,24,25}$ suggests a correlation with the tipfocused $\mathrm{Ca}^{2+}$ gradient which determines the direction of pollen tube growth..$^{10,18,19,21,23-26}$ The polcalcins are rapidly washed out of the cytosol upon pollen hydration, 10,13,18,19,24,25,27 which explains the allergenicity of the intracellular polcalcins. Although the polcalcins are minor allergens in terms of IgE binding prevalence, human basophil histamine release assays and skin prick tests revealed remarkable allergenic potency in affected patients. ${ }^{12,19}$ In addition, sensitization to polcalcins appears to be associated with allergic cross-reactions to other calcium-binding pollen allergens like Bet v 3 from birch (Betula verrucosa) and Jun o 4 from prickly juniper (Juniperus oxycedrus) ${ }^{28}$ or Ole e 8 from olive (Olea europaea), ${ }^{29}$ although their sequence identity with the polcalcins is almost completely restricted to the EF-hand motifs themselves. Since $\mathrm{Ca}^{2+}$ depletion decreases binding of the $\operatorname{IgE}$ antibodies of many patients to the polcalcins ${ }^{10-12,16,19-21,29}$ sitedirected mutagenesis of the $\mathrm{Ca}^{2+}$-ligating sidechains that abolishes the ability of the polcalcins to bind $\mathrm{Ca}^{2+}$ has been proposed for the production of hypoallergenic vaccines for a patient-tailored specific immunotherapy with reduced anaphylactic side effects. ${ }^{12,16,19,23,26}$ The recently determined crystal structure of holo Phl p 7 (Protein Data Bank (PDB) access code $1 \mathrm{~K} 9 \mathrm{U}$ ) surprisingly revealed a domainswapped dimer. ${ }^{26}$ Since the three-dimensional structure of at least one more polcalcin is a prerequisite for a detailed understanding of the clinically observed $\operatorname{IgE}$ cross-reactivity on the structural level, we determined the high-resolution three-dimensional structure of holo Bet $\mathrm{v} 4$ in solution and verified its oligomerization state by NMR and analytical ultracentrifugation measurements.

\section{Results and Discussion}

\section{Sequence-specific resonance assignments and structure determination}

Sequence-specific resonance assignment allowed identification of all of the 81 backbone amide resonances (Figure 2) and all of the $\mathrm{H}^{\alpha}, \mathrm{C}^{\alpha}$, and $\mathrm{C}^{\beta}$ chemical shifts. A total of $934{ }^{1} \mathrm{H},{ }^{13} \mathrm{C}$, and ${ }^{15} \mathrm{~N}$ chemical shifts out of 1058 expected $(88 \%)$ had been determined upon completion of the sidechain resonance assignment process, 498 of which were proton chemical shifts $(93 \%$ of the 536 expected). In addition, we were able to measure 66 intraresidue ${ }^{3} \mathrm{HNH}_{\mathrm{HN} \alpha}$ scalar coupling constants, three interresidue ${ }^{3 \mathrm{~h}} \mathrm{~J}_{\mathrm{NC}}$ scalar coupling constants across hydrogen bonds (Table 1), and $68 D_{\mathrm{NH}}$ dipolar coupling constants. On this basis a total of 1671 experimental restraints could be derived for the structure calculation (Table 2). In particular, the dispersion of the amide proton resonances allowed the identification of $1269{ }^{15} \mathrm{~N}-\mathrm{NOESY}-$ HSQC cross-peaks, thus providing the largest con-
Table 1. Scalar coupling constants across hydrogen bonds

\begin{tabular}{llc}
\hline Donor & Acceptor-bound carbon & ${ }^{3 h} J_{\mathrm{NC}}(\mathrm{Hz})$ \\
\hline Ile26 N & Ile61 C & -0.575 \\
Leu31 N & Ser27 C & -0.537 \\
Phe66 N & Ser62 C & -0.541 \\
\hline
\end{tabular}

tribution. The 2D $\left[{ }^{1} \mathrm{H},{ }^{1} \mathrm{H}\right]$ nuclear Overhauser enhancement spectroscopy (NOESY) spectrum in ${ }^{2} \mathrm{H}_{2} \mathrm{O}$ provided 165 additional distance restraints, which were particularly valuable since many of them are based on long-range nuclear Overhauser effects (NOEs) involving aromatic side-chains expected to form hydrophobic cores (Figure 3). The $\mathrm{Ca}^{2+}$ coordination does not involve any protons and hence the NMR spectra do not contain any direct structural information about the $\mathrm{Ca}^{2+}$ coordination itself, which was assumed to follow the canonical EF-hand pattern ${ }^{30}$ and modeled accordingly. This assumption is supported by several conclusive lines of evidence: first, the corresponding amino acid residues are highly conserved (Figure 1), the mutations D19A and/or D54A prevented $\mathrm{Ca}^{2+}$ binding to the affected EFhand(s) of Bet v $4,{ }^{10}$ and similar mutational studies with other polcalcins also support the canonical EF-hand $\mathrm{Ca}^{2+}$ ligation. ${ }^{16,26}$ Second, the $\mathrm{Ca}^{2+}$ binding loops of holo Bet $\mathrm{v} 4$ show the characteristic chemical shift pattern of canonical EF-hands like those of holo calmodulin, ${ }^{31}$ especially the strong $\mathrm{Ca}^{2+}$ induced shift of the amide resonances of Gly24 and Gly59 to low field (Figure 2) upon formation of short hydrogen bonds with the $\mathrm{O}^{\delta 2}$ atoms of the $\mathrm{Ca}^{2+}$ ligating carboxyl groups of Asp19 and Asp54, respectively. Third, the backbone conformation of the $\mathrm{Ca}^{2+}$-binding loops of holo Bet $\mathrm{v} 4$ is identical with canonical EF-hands, and the experimental restraints for the $\mathrm{Ca}^{2+}$-ligating side-chains are also consistent with the canonical EF-hand $\mathrm{Ca}^{2+}$ ligation. Finally, the slowly exchanging hydroxyl protons of Ser27 and Ser62 indicate that in addition to their function as helix N-caps by accepting hydrogen bonds from the amide groups of Glu30 and Glu65, respectively, these hydroxyl groups also serve as hydrogen bond donors to stabilize the network of water molecules contributing the seventh ligand of each of the two $\mathrm{Ca}^{2+}$ (Figure 5), which is not provided by canonical EFhand proteins. ${ }^{30}$ The 25 accepted structures of holo Bet $\mathrm{v} 4$ showed no single distance restraint violation of more than $0.30 \AA$ and no systematic violation of more than $0.15 \AA$. An analysis with PROCHECK $3.4^{32}$ revealed a virtually perfect Ramachandran plot with $94.2 \%$ of the non-glycine and non-proline residues in the most favored regions and the remainder in the additional allowed regions. The low value of $0.18( \pm 0.06) \AA$ for the cross-validated root mean square deviations (RMSDs) from the test set distance restraints of the set of 210 accepted structures out of a total of 600 structures calculated for complete cross-validation ${ }^{33}$ 


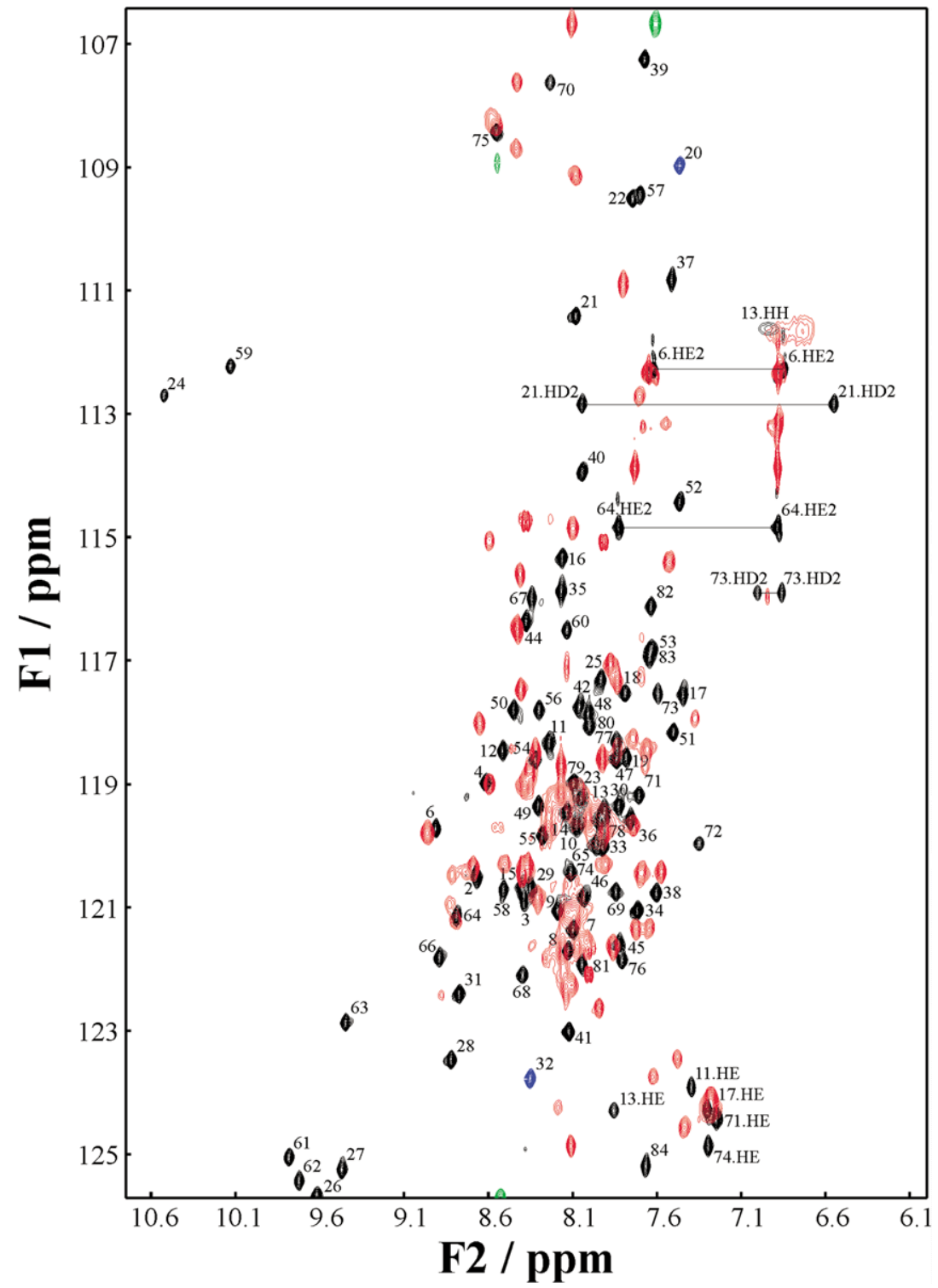

Figure 2. Overlay of the $\left[{ }^{1} \mathrm{H},{ }^{15} \mathrm{~N}\right]$ HSQC spectra of $0.7 \mathrm{mM}$ uniformly ${ }^{15} \mathrm{~N}$-labeled apo Bet $\mathrm{v} 4$ (positive signals in red, negative signals in green) and of $1.5 \mathrm{mM}$ uniformly ${ }^{13} \mathrm{C} /{ }^{15} \mathrm{~N}$-labeled holo Bet v 4 (positive signals in black, negative signals in blue) in $20 \mathrm{mM}$ sodium acetate (pH 6.0) in $\mathrm{H}_{2} \mathrm{O} /{ }^{2} \mathrm{H}_{2} \mathrm{O}(9: 1)$ recorded at $298 \mathrm{~K}$ on Bruker Avance400 and DMX750 NMR spectrometers, respectively. Negative resonances are aliased in the indirect ${ }^{15} \mathrm{~N}$ dimension $F 1$. Upon $\mathrm{Ca}^{2+}$ depletion the well-dispersed amide proton resonances of holo Bet $\mathrm{v} 4$ labeled according to their residue numbers reversibly lose most of their chemical shift dispersion, especially those shifted to low field, which are all located in the $\mathrm{Ca}^{2+}$ binding loops. provides further evidence for the excellent quality of the solution structure of holo Bet $\mathrm{v} 4$.

\section{Description of the structure and dynamics}

Except for the $\mathrm{NH}_{2}$-terminal residues from Ala1 to His4, holo Bet v 4 shows a well defined structure in solution (Figure 4) with an average atomic RMSD from the average structure of $0.22 \AA$ for the backbone and $0.57 \AA$ for all heavy atoms. A schematic representation of the solution structure of holo Bet v 4 (Figure 5) reveals two canonical EF-hands in the open conformation formed by the helices $\alpha_{1}$ (residues 5-18) and $\alpha_{2}$ (28-38, with the last turn following a 3 o geometry) with an interhelical angle ${ }^{34}$ of $101.5( \pm 0.9)^{\circ}$ and $\alpha_{3}(43-53)$ and $\alpha_{4}(63-72)$ with an interhelical angle of $96.9( \pm 1.0)^{\circ}$, which are paired via a short antiparallel $\beta$-sheet formed by the strands $\beta_{1}(25-27)$ and $\beta_{2}(60-62)$. The two EF-hands are also connected by a large hydrophobic core around the aromatic side-chain of the highly conserved Phe15 (Figure 1), suggesting that the almost complete loss of IgE reactivity of a holo Bet $\mathrm{v} 4$ fragment lacking the $\mathrm{NH}_{2}$-terminal residues up to Phe $15^{11}$ is caused by disruption of the native fold. The $\mathrm{COOH}$-terminal residues 74-84, which are highly conserved among the polcalcins but discriminate the polcalcins from the other EF-hand proteins (Figure 1) and can therefore be expected to be of particular significance for both their allergenicity and their physiological function, form an additional helix $\alpha_{5}$ with pronounced amphiphilicity, whose hydrophobic face packs into the hydrophobic groove formed by helices $\alpha_{1}$ and $\alpha_{2}$ (Figure 5). However, this packing still leaves a major part of this hydrophobic groove solvent-exposed (Figure 6). Analysis of the ${ }^{15} \mathrm{~N}$ relaxation data (Figure 3 ) and spectral density values obtained by reduced spectral density mapping (RSDM) (data not shown) reveals that the $\mathrm{NH}_{2}$-terminal residues are indeed highly flexible, with large-amplitude backbone motions 
Table 2. Summary of the structure calculation of holo Bet v 4

\begin{tabular}{|c|c|c|}
\hline $\begin{array}{l}\text { Experimental restraints used for the structure calculation } \\
\text { Intraresidual NOEs }\end{array}$ & & 414 \\
\hline \multirow[t]{3}{*}{ Interresidual NOEs } & Sequential & 443 \\
\hline & Medium-range & 394 \\
\hline & Long-range & 191 \\
\hline Dihedral angle restraints & & 50 \\
\hline Hydrogen bonds (two distance restraints each) & & 22 \\
\hline Dipolar coupling restraints & & 61 \\
\hline${ }^{13} \mathrm{C}^{\alpha} /{ }^{13} \mathrm{C}^{\beta}$ chemical shift restraints & & 74 \\
\hline \multicolumn{3}{|l|}{ Molecular dynamics simulation statistics } \\
\hline \multirow[t]{8}{*}{ Energies $(\mathrm{kcal} / \mathrm{mol})$} & Total & $55.8 \pm 1.5$ \\
\hline & Bond lengths & $4.27 \pm 0.12$ \\
\hline & Bond angles & $21.4 \pm 0.8$ \\
\hline & Improper angles & $8.8 \pm 0.3$ \\
\hline & van-der-Waals Repulsion & $5.7 \pm 0.6$ \\
\hline & Distance restraints & $13.2 \pm 0.6$ \\
\hline & Dipolar coupling restraints & $2.5 \pm 0.3$ \\
\hline & Dihedral angle restraints & $0.0003 \pm 0.0008$ \\
\hline \multirow[t]{2}{*}{ RMSDs from ideal distances $(\AA)$} & Bond lengths & $0.00180 \pm 0.00003$ \\
\hline & Distance restraints & $0.0133 \pm 0.0003$ \\
\hline \multirow[t]{3}{*}{ RMSDs from ideal angles (deg.) } & Bond angles & $0.243 \pm 0.005$ \\
\hline & Dihedral angles & $0.338 \pm 0.004$ \\
\hline & Dihedral angle restraints & $0.002 \pm 0.003$ \\
\hline \multirow[t]{2}{*}{ RMSDs from chemical shifts (ppm) } & ${ }^{13} \mathrm{C}^{\alpha}$ & $1.18 \pm 0.03$ \\
\hline & ${ }^{13} \mathrm{C}^{\beta}$ & $0.84 \pm 0.03$ \\
\hline RMSDs from dipolar couplings $(\mathrm{Hz})$ & $D_{\mathrm{NH}}$ & $0.202 \pm 0.010$ \\
\hline Radius of gyration of the regular secondary structure $(\AA)$ & & $11.78 \pm 0.03$ \\
\hline \multicolumn{3}{|l|}{ Atomic RMSDs from the average structure $(\AA)$} \\
\hline & Backbone & Heavy atoms \\
\hline Overall $^{\mathbf{b}}$ & $0.41 \pm 0.11$ & $0.69 \pm 0.08$ \\
\hline Regular secondary structure ${ }^{\mathbf{a}}$ & $0.22 \pm 0.08$ & $0.57 \pm 0.09$ \\
\hline \multicolumn{3}{|l|}{$\begin{array}{l}\text { tandard deviation. } \\
\text { a Residues 5-84. } \\
\text { b Residues 1-84. }\end{array}$} \\
\hline
\end{tabular}

on the sub-nanosecond time-scale as revealed by low generalized order parameters $S^{2}$. The short linker region between the two EF-hands formed by residues Gly39 to Ser42 also has increased backbone flexibility on the sub-nanosecond time-scale. In contrast, the amide group of Phe18, whose aromatic side-chain constitutes a key element of a large hydrophobic core connecting and fixing the helices $\alpha_{1}, \alpha_{2}$, and $\alpha_{5}$, is involved in exchange processes on a slower time-scale as indicated by enhanced transverse relaxation especially at $750 \mathrm{MHz}$. Enhanced transverse relaxation at $750 \mathrm{MHz}$ also suggests that the antiparallel $\beta$ sheet pairing of the two EF-hands is affected by exchange processes on a slower time-scale. The dynamics of the amphipathic $\mathrm{COOH}$-terminal helix $\alpha_{5}$ appears to be more complex, with both moderate sub-nanosecond motions as indicated by slightly reduced $\left\{{ }^{1} \mathrm{H}\right\}{ }^{15} \mathrm{~N}$ NOE values and exchange processes on a slower time-scale as indicated by slightly enhanced transverse relaxation especially at $750 \mathrm{MHz}$.

\section{Hydrodynamics and oligomerization state}

The ratios between ${ }^{15} \mathrm{~N}$ longitudinal and transverse relaxation rates at $600 \mathrm{MHz}$ also allowed the determination of the rotational diffusion tensor based on the lowest energy structure of holo Bet $\mathrm{v}$ 4. In the fully anisotropic case, the principal axes of the rotational diffusion tensor coincide with the corresponding principal axes of the tensor of inertia with deviations of less than about $10^{\circ}$. The eigenvalues of $3.26 \times 10^{7} \mathrm{~s}^{-1}, 2.84 \times 10^{7} \mathrm{~s}^{-1}$, and $2.67 \times 10^{7} \mathrm{~s}^{-1}$ correspond to overall tumbling autocorrelation times ${ }^{35}$ of $\tau_{1}=6.0 \mathrm{~ns}, \tau_{2}=5.8 \mathrm{~ns}$, $\tau_{3}=5.4 \mathrm{~ns}, \tau_{+}=5.5 \mathrm{~ns}$, and $\tau_{-}=5.9 \mathrm{~ns}$. However, a prolate axially symmetric rotational diffusion tensor with eigenvalues of $3.26 \times 10^{7} \mathrm{~s}^{-1}$ and $2.75 \times 10^{7} \mathrm{~s}^{-1}$ corresponding to overall tumbling autocorrelation times ${ }^{35}$ of $\tau_{\mathrm{A}}=6.1 \mathrm{~ns}, \tau_{\mathrm{B}}=5.9 \mathrm{~ns}$, and $\tau_{C}=5.4 \mathrm{~ns}$ constitutes a satisfying approximation for our purposes. NMR translational diffusion measurements yielded a hydrodynamic radius of $17.8( \pm 0.4) \AA$ corresponding to a compaction factor $^{36}$ of $94( \pm 21) \%$ for holo Bet v 4 . A continuous size distribution ${ }^{37-39}$ was fitted to the results of sedimentation velocity experiments performed on holo Bet $\mathrm{v} 4$ at four different concentrations between $120 \mu \mathrm{M}$ and $900 \mu \mathrm{M}$. A best-fit weightaveraged ratio of the frictional coefficient of the protein $f$ to that of an anhydrous sphere $f_{0}$ of 1.250 for all species and concentrations was also obtained with this fit. The resulting continuous size sedimentation coefficient profiles $c(s)$ demonstrate that holo Bet $\mathrm{v} 4$ is predominantly monomeric 

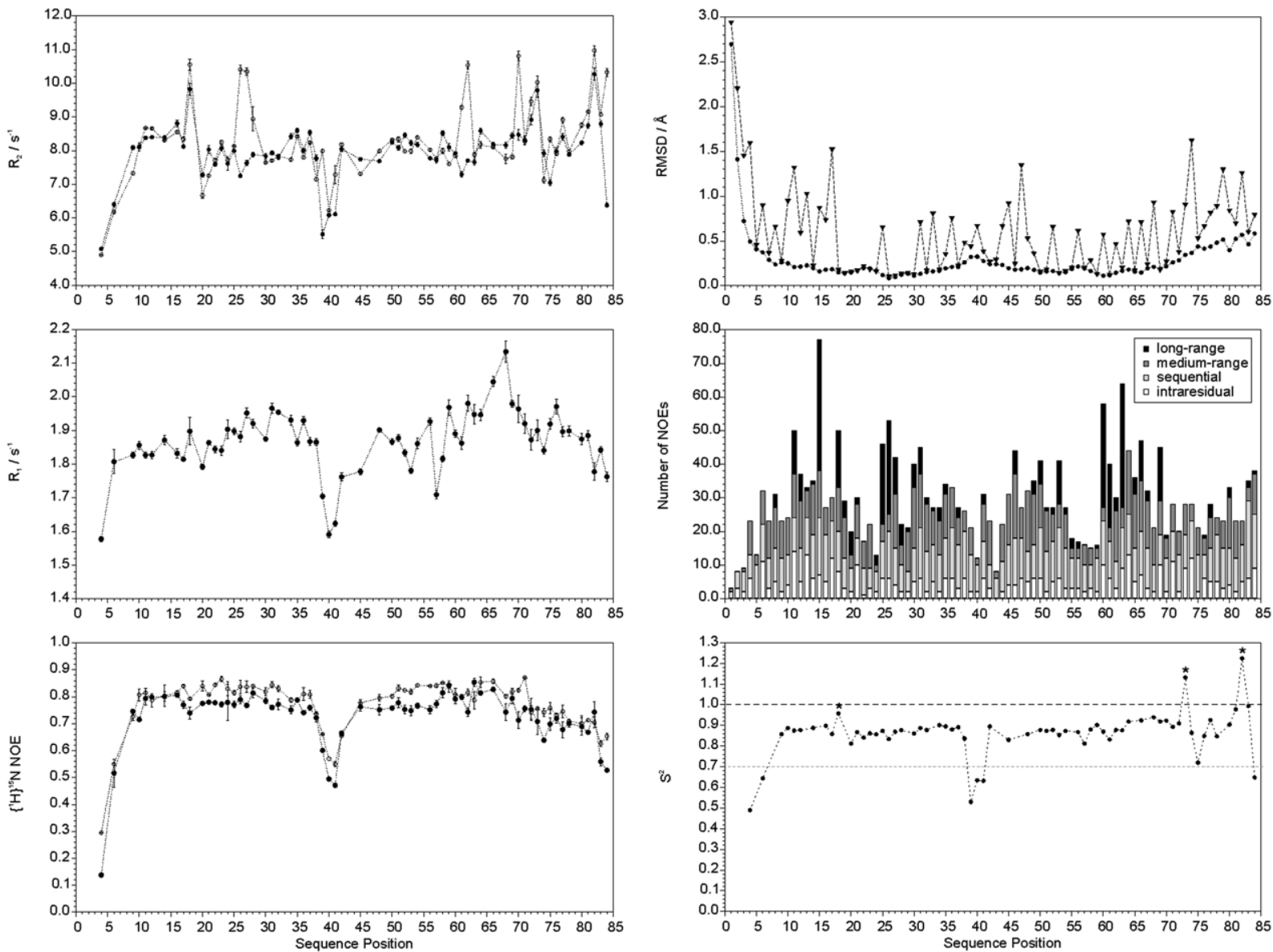

Figure $3 .{ }^{15} \mathrm{~N}$ transverse (top left) and longitudinal (center left) relaxation rates, $\left\{{ }^{1} \mathrm{H}\right\}{ }^{15} \mathrm{~N}$ NOE values (bottom left), atomic RMSDs from the average structure (top right), distribution of NOEs (center right), and generalized order parameters $S^{2}$ of the sub-nanosecond internal motion (bottom right). ${ }^{15} \mathrm{~N}$ relaxation data at $600 \mathrm{MHz}$ and $750 \mathrm{MHz}$ are represented by filled and open circles, respectively, with the corresponding error bars. Backbone RMSDs are indicated by filled circles, side-chain heavy atom RMSDs by filled triangles. The low number of NOE distance restraints found for the flexible $\mathrm{NH}_{2}$-terminal residues from Ala1 to His4 leads to very high atomic RMSDs. The residues with a high number of NOEs are predominantly aromatic (e.g. Phe15, Phe60 and Phe63), emphasizing the importance of the 2D [ $\left.{ }^{1} \mathrm{H},{ }^{1} \mathrm{H}\right]$ NOESY in ${ }^{2} \mathrm{H}_{2} \mathrm{O}$ for the structure determination. Generalized order parameters $S^{2}$ for residues involved in exchange processes are artificially overestimated due to exchange contributions to the spectral density at zero frequency ${ }^{80}$ and therefore marked by asterisks.

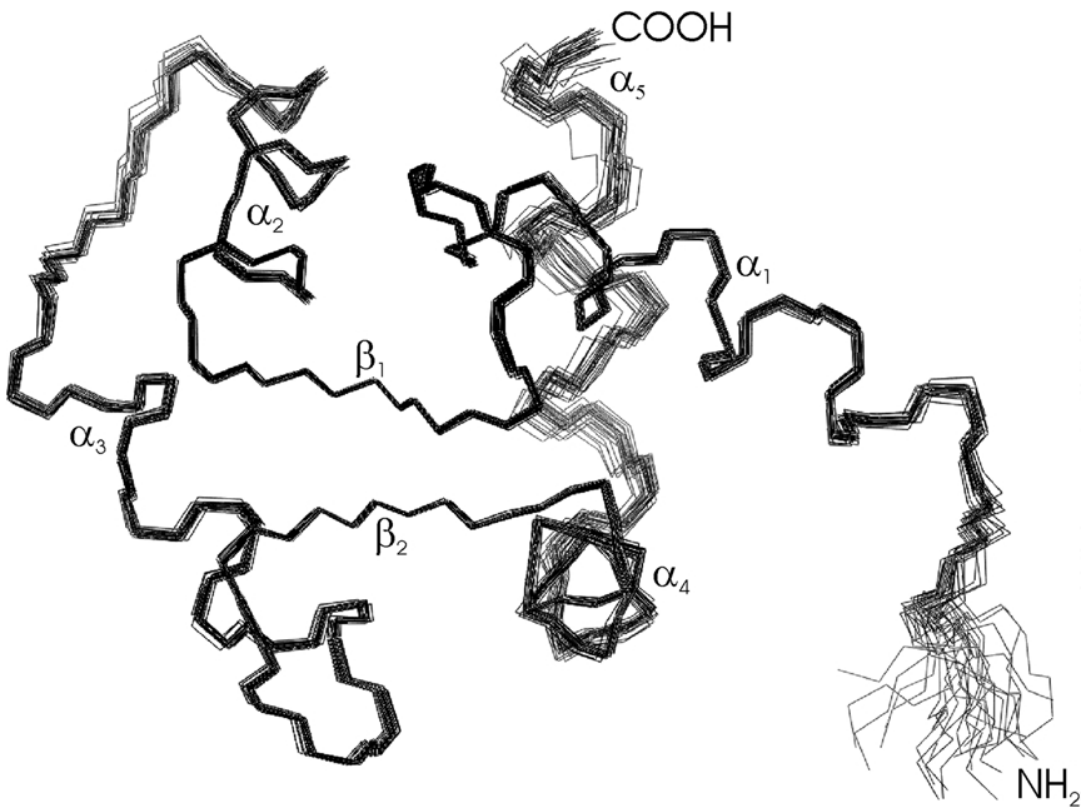

Figure 4. Backbone overlay of the 25 accepted structures of holo Bet $\mathrm{v}$ 4. Except for the flexible $\mathrm{NH}_{2}$-terminal residues from Ala1 to His4 on the right the structures are in excellent agreement, especially as far as the two EF-hands are concerned. The overlay was performed using Sybyl 6.5 (Tripos Inc., St. Louis, MO, USA). 


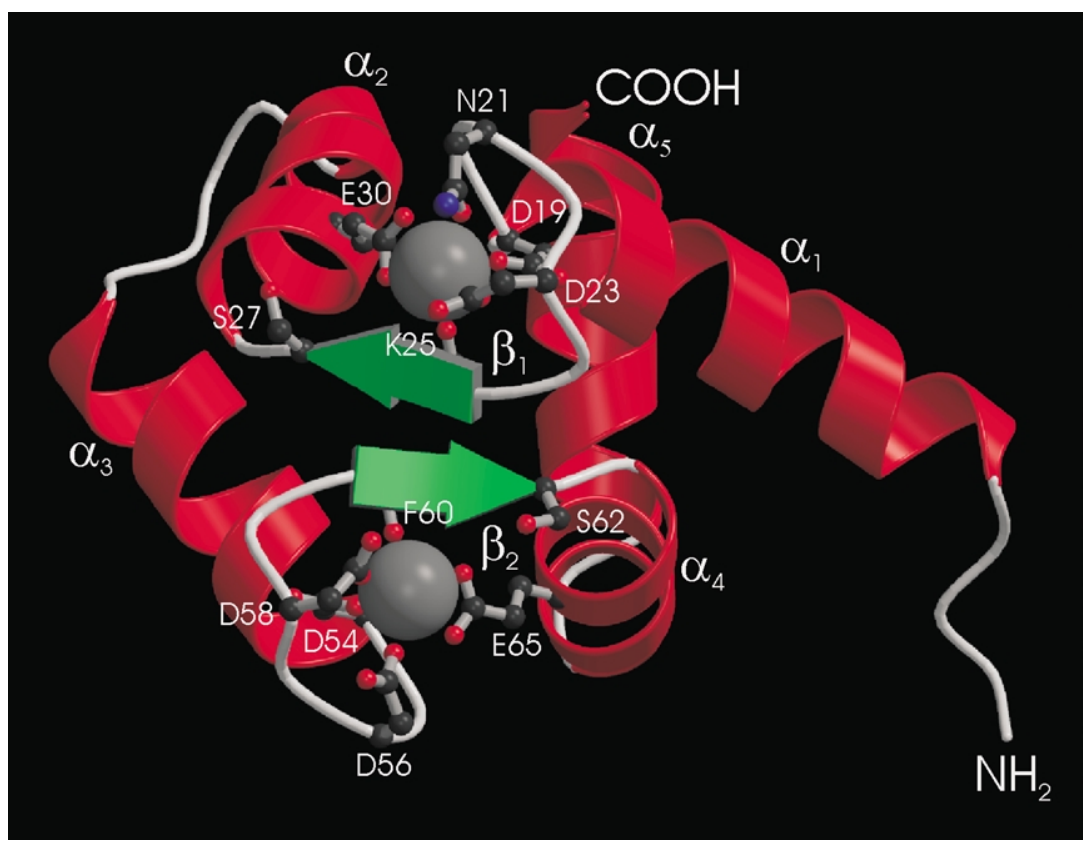

Figure 5. Schematic representation of the secondary structure elements based on the lowest energy structure of holo Bet v 4 . Same view as in Figure 4. The coordination of each of the two $\mathrm{Ca}^{2+}$ (large gray balls) by Asp19 $\left(\mathrm{O}^{\delta 1}\right.$ at ligand position $\left.x\right)$, Asn21 $\left(\mathrm{O}^{\delta 1}\right.$ at $\left.y\right), \operatorname{Asp} 23\left(\mathrm{O}^{\delta 1}\right.$ at $\left.z\right)$, Lys25 $(\mathrm{O}$ at $-y)$, and Glu30 $\left(\mathrm{O}^{\varepsilon 1}\right.$ and $\mathrm{O}^{\varepsilon 2}$ at $-z)$ or Asp54 $\left(\mathrm{O}^{\delta 1}\right.$ at $\left.x\right)$, Asp56 $\left(\mathrm{O}^{\delta 1}\right.$ at $\left.y\right), \mathrm{Asp} 58\left(\mathrm{O}^{\delta 1}\right.$ at $\left.z\right)$, Phe60 $(\mathrm{O}$ at $-y)$, and Glu65 $\left(\mathrm{O}^{\varepsilon 1}\right.$ and $\mathrm{O}^{\varepsilon 2}$ at $-z$ ) at the vertices of a pentagonal bipyramid is shown in balland-stick-representation with carbon, nitrogen, and oxygen atoms color-coded dark gray, blue, and red, respectively. Like in other canonical EF-hands the ligand position $-x$ appears to be occupied by water molecules stabilized by hydrogen bonds with the slowly exchanging hydroxyl proton of Ser27 or Ser62. The hydroxyl groups of Ser27 and most likely Ser62 (the definition of the hydroxyl group of Ser62 by the experimental restraints is not precise enough for conclusive judgement) also serve as N-caps of the helices $\alpha_{2}$ and $\alpha_{4}$ by accepting hydrogen bonds from the amide groups of Glu30 and Glu65, respectively. The Figure was drawn with MolScript $1.4^{92}$ and rendered with Raster3D 2.2a. ${ }^{93}$

in solution (Figure 7). In addition, from the converted molar mass distributions $c(M)$ another species of a molar mass approximately corresponding to that of dimeric holo Bet v 4 is observed at low abundance (about $15 \%$ of the sum of the two observed species of holo Bet $\mathrm{v} 4$ ). The average hydrodynamic parameters over the different concentrations are $M=10.5( \pm 0.3) \mathrm{kDa}, s=1.365$ $( \pm 0.019) \mathrm{S}$, and $D=1.175 \times 10^{-6}\left( \pm 0.014 \times 10^{-6}\right) \mathrm{cm}^{2} /$ second for monomeric holo Bet $\mathrm{v} 4$, and $M=$ $20.4( \pm 1.1) \mathrm{kDa}, \mathrm{s}=2.12( \pm 0.08) \mathrm{S}$, and $D=0.944 \times$ $10^{-6}\left( \pm 0.016 \times 10^{-6}\right) \mathrm{cm}^{2} /$ second for dimeric holo Bet $\mathrm{v} 4$, corresponding to hydrodynamic radii of $17.9( \pm 0.2) \AA$ and $22.2( \pm 0.2) \AA$, respectively. A noninteracting discrete species model was also fitted to the sedimentation velocity data, confirming the presence of a monomeric (more than $80 \%$ ) and a dimeric (less than 20\%) fraction (data not shown). An independent confirmation was obtained by fitting a non-interacting discrete species model to the results of sedimentation equilibrium experiments at initial concentrations between $120 \mu \mathrm{M}$ and $900 \mu \mathrm{M}$. The monomeric molar mass was kept fixed at the theoretical value of $9.396 \mathrm{kDa}$. The low RMSD values demonstrate the high quality of these fits. Averaged over all initial concentrations the monomeric fraction comprised $88.5( \pm 1.7) \%$ of the total holo Bet $\mathrm{v} 4$ content, the molar mass of the other species in solution varied between $25 \mathrm{kDa}$ and $33 \mathrm{kDa}$. To determine whether holo Bet $\mathrm{v} 4$ follows a self-association pattern, a monomer-dimer or a monomer-trimer model were also fitted to the sedimentation equilibrium data (data not shown). The global fit based on data at $16,000 \mathrm{rpm}, 20,000 \mathrm{rpm}$, and 24,000 rpm and initial concentrations in the range of 120$900 \mu \mathrm{M}$ was not of sufficient quality to support the monomer-dimer $\left(K_{1,2}=446 \mathrm{M}^{-1}\right.$, RMSD 0.086) or the monomer-trimer $\left(K_{1,3}=5 \times 10^{4} \mathrm{M}^{-2}\right.$, RMSD $0.157)$ model as indicated by the non-random distribution of points about the zero value of the residual plots, the high RMSDs, and the extremely low association constants $K_{1, n}$. In addition, the fact that the curves of apparent molar mass versus initial concentration do not superimpose in the diagnostic graph indicates that a concentration-dependent reversible self-association can be discounted. Therefore, on the time-scale of analytical ultracentrifugation of several hours the dimer appears not to be in equilibrium with the monomer and suggests that holo Bet $\mathrm{v} 4$ does not self-associate under the solution conditions employed. For comparison, the hydrodynamic parameters of holo Bet v 4 were also calculated based on a prolate ellipsoid of revolution ${ }^{35,40,41}$ with semi-axes of $19.5 \AA$ and $13.6 \AA$, which has the same tensor of inertia and radius of gyration as the 25 accepted structures of holo Bet v 4 in the prolate axially symmetric approximation, assuming a hydration layer of $2.8 \AA$ and a viscosity of $0.911 \times 10^{-3} \mathrm{~Pa}$ s for $\mathrm{H}_{2} \mathrm{O} /{ }^{2} \mathrm{H}_{2} \mathrm{O}$ (9:1) obtained from linear interpolation of the viscosities of $\mathrm{H}_{2} \mathrm{O}$ and ${ }^{2} \mathrm{H}_{2} \mathrm{O}$ at $298 \mathrm{~K} .{ }^{42}$ This simple model allows the quantitative prediction of both the translational and rotational diffusion of holo Bet v 4 to remarkable accuracy, with deviations from the experimental values of only a few percent (Table 3).

NMR translational diffusion measurements on apo Bet $\mathrm{v} 4$ yielded a slightly increased hydrodynamic radius of $18.9( \pm 0.4) \AA$ corresponding to 


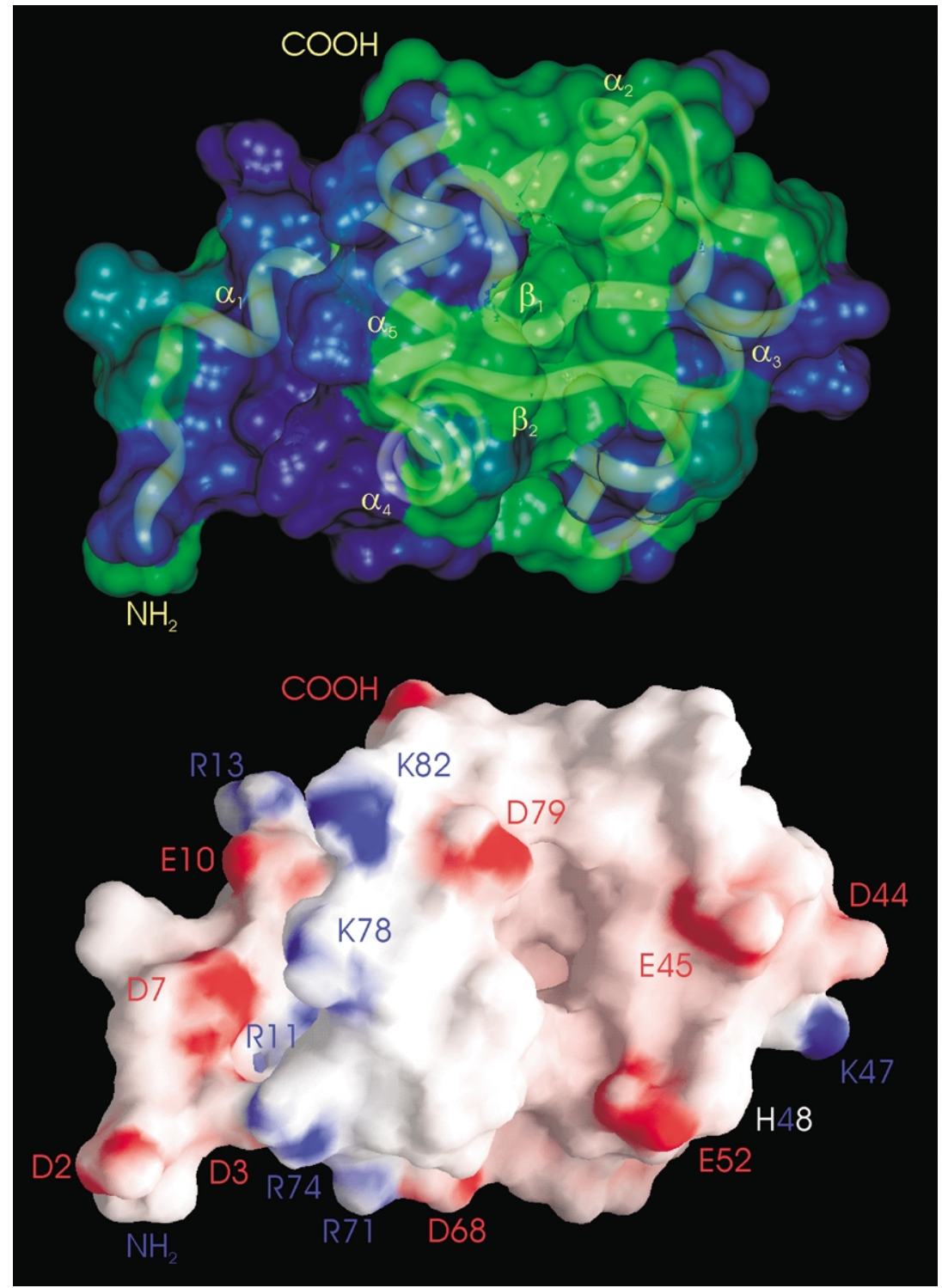

Figure 6. Connolly surface of the lowest energy structure of holo Bet $\mathrm{v} 4$ colored according to hydrophobicity (top; backbone yellow, hydrophobic residues green, hydrophilic residues blue) or electrostatic potential (bottom; negative potential red, positive potential blue). Opposite view as in Figures 4 and 5 . The electric charge of the sidechain of His48 depends on $\mathrm{pH}$, at $\mathrm{pH} 6.0$ it is predominantly protonated. The $\mathrm{COOH}$-terminal helix $\alpha_{5}$ does not cover the hydrophobic groove lined by negatively charged residues completely. Formation of the domain-swapped dimer of holo Phl p 7 closes this hydrophobic groove, resulting in a hydrophobic cavity which is no longer solventaccessible. $^{26}$ The Figure was prepared with InsightII 98.0 (Molecular Simulations Inc., San Diego, CA, USA) and GRASP 1.2. ${ }^{94}$

a compaction factor ${ }^{36}$ of $84( \pm 20) \%$. The continuous size distribution fits excellently to the results of sedimentation velocity experiments on apo Bet $\mathrm{v} 4$ at concentrations of 150,340 , and $680 \mu \mathrm{M}$ (data not shown). The best-fit weight-averaged frictional ratio was $f / f_{0}=1.261$ for all concentrations. The calculated continuous size sedimentation coefficient and molar mass profiles show one major

Table 3. Hydrodynamic properties of apo and holo Bet $\mathrm{v} 4$

\begin{tabular}{|c|c|c|c|c|}
\hline & & $\mathrm{NMR}^{\mathrm{a}}$ & Sedimentation velocity $\mathbf{b}^{\mathbf{b}}$ & Prediction $^{c}$ \\
\hline \multirow[t]{2}{*}{ apo Bet v 4} & Hydrodynamic radius $(\AA)$ & $18.9 \pm 0.4$ & $18.2 \pm 0.1$ & \\
\hline & Hydrodynamic radius $(\AA)$ & $17.8 \pm 0.4$ & $\begin{array}{l}17.9 \pm 0.2(\approx 85 \%) \\
22.2 \pm 0.2(\approx 15 \%)\end{array}$ & 18.3 \\
\hline holo Bet v 4 & Overall rotational diffusion autocorrelation times (ns) & $\begin{array}{l}6.1 \\
5.9 \\
5.4\end{array}$ & & $\begin{array}{l}6.5 \\
6.2 \\
5.4\end{array}$ \\
\hline
\end{tabular}

\footnotetext{
${ }^{\text {a }}$ Hydrodynamic radii with their standard errors taken from NMR translational diffusion measurements and overall rotational diffusion autocorrelation times calculated from ${ }^{15} \mathrm{~N}$ NMR relaxation measurements in the prolate axially symmetric approximation.

b Hydrodynamic radii calculated from sedimentation velocity experiments. Values are average values over the different protein concentrations in the form average value \pm standard deviation. The relative amount of each species is given in parentheses.

c Prediction based on a prolate ellipsoid of revolution with semi-axes of $19.5 \AA$ and $13.6 \AA$, which has the same tensor of inertia and radius of gyration as the 25 accepted structures of holo Bet $\mathrm{v} 4$ in the prolate axially symmetric approximation, plus a hydration layer of $2.8 \AA$.
} 

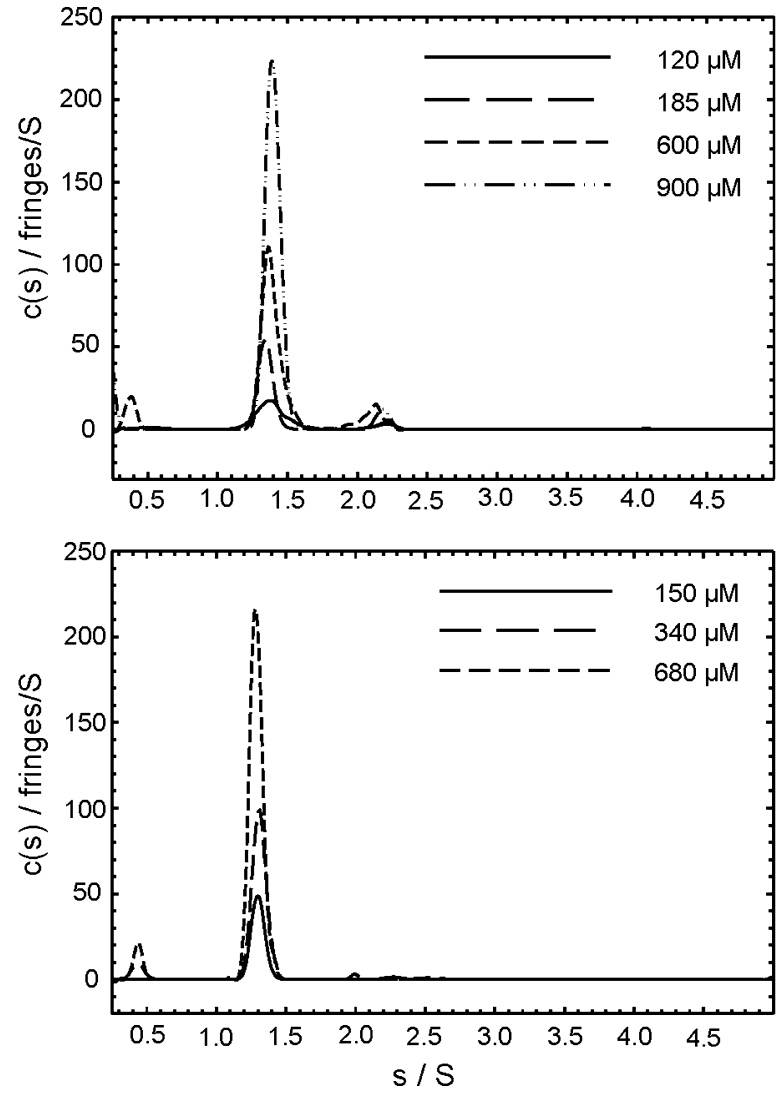

Figure 7. Sedimentation velocity analysis. Comparison of the continuous size distributions $c(s)$ versus sedimentation coefficient $s$ of holo Bet $\mathrm{v} 4$ at four different loading concentrations (top) as well as of apo Bet $\mathrm{v} 4$ at three different loading concentrations (bottom). In all cases the best-fit weight-averaged frictional ratio $f / f_{0}$ was 1.250 and 1.261 for holo and apo Bet $v$ 4, respectively, with maximum entropy regularization at confidence levels of $p=0.68$ and at a resolution of sedimentation coefficients or molar masses of 150 .

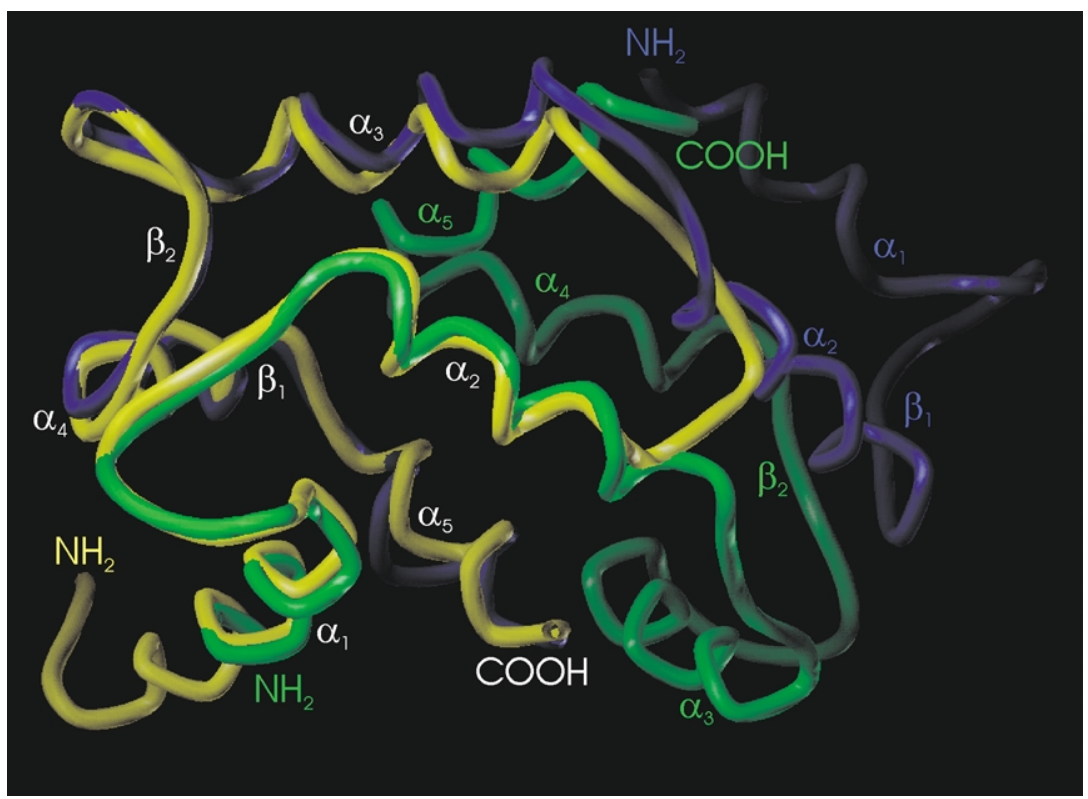

peak comprising $91.3 \%$ of the sample (Figure 7). The average hydrodynamic parameters over the different concentrations are $M=10.28( \pm 0.08) \mathrm{kDa}$, $s=1.290( \pm 0.015) \mathrm{S}$, and $D=1.156 \times 10^{-6}( \pm 0.007 \times$ $\left.10^{-6}\right) \mathrm{cm}^{2} /$ second, corresponding to a hydrodynamic radius of $18.2( \pm 0.1) \AA$. This molar mass estimate is in accordance with the calculated molar mass of $9.316 \mathrm{kDa}$, clearly indicating the presence of a single monomeric species. In support of this finding global analysis of sedimentation equilibrium experiments on apo Bet $\mathrm{v} 4$ at concentrations of 150,340 , and $680 \mu \mathrm{M}$ converges to a molar mass of $9.895 \mathrm{kDa}$ (data not shown).

\section{Comparison with Phl p 7}

The excellent agreement of the hydrodynamic parameters derived from different experimental methods (Table 3) leaves no doubt that both apo and holo Bet $\mathrm{v} 4$ are predominantly monomeric in all samples tested, corroborating the results of early cross-linking experiments. ${ }^{10}$ In contrast, the recently determined crystal structure of holo Phl p 7 surprisingly revealed a domain-swapped dimeric assembly, and size-exclusion chromatography indicated that both apo and holo Phl p 7 are exclusively dimeric at neutral and slightly acidic $\mathrm{pH} .{ }^{26}$ In spite of the different oligomerization state the secondary and tertiary structure of holo Bet $\mathrm{v}$ 4 and holo Phl p 7 are remarkably similar (Figure 8), with a backbone atomic RMSD of $1.30 \AA$ for all but the four residues Gly39 to Ser42 linking the EF-hands. Interestingly, this even holds for the COOH-terminal helix $\alpha_{5}$, in spite of its marked distortion in holo Phl p 7 to alleviate steric clashes at the tightly packed dimer interface. ${ }^{26}$ Hence, most of the IgE epitopes are unlikely to be affected by the domain-swapping dimerization, which suggests that canonical monomers and

Figure 8. Backbone overlay of the average solution structure of holo Bet $\mathrm{v} 4$ (yellow) with the $\mathrm{NH}_{2}$-terminal EF-hand of the first monomer (green) and the $\mathrm{COOH}$-terminal EF-hand of the second monomer (blue) of the crystal structure of holo Phl p 7. Apart from the domain-swapping dimerization the tertiary fold is almost identical. The overlay was performed using Sybyl 6.5 (Tripos Inc., St. Louis, MO, USA). 

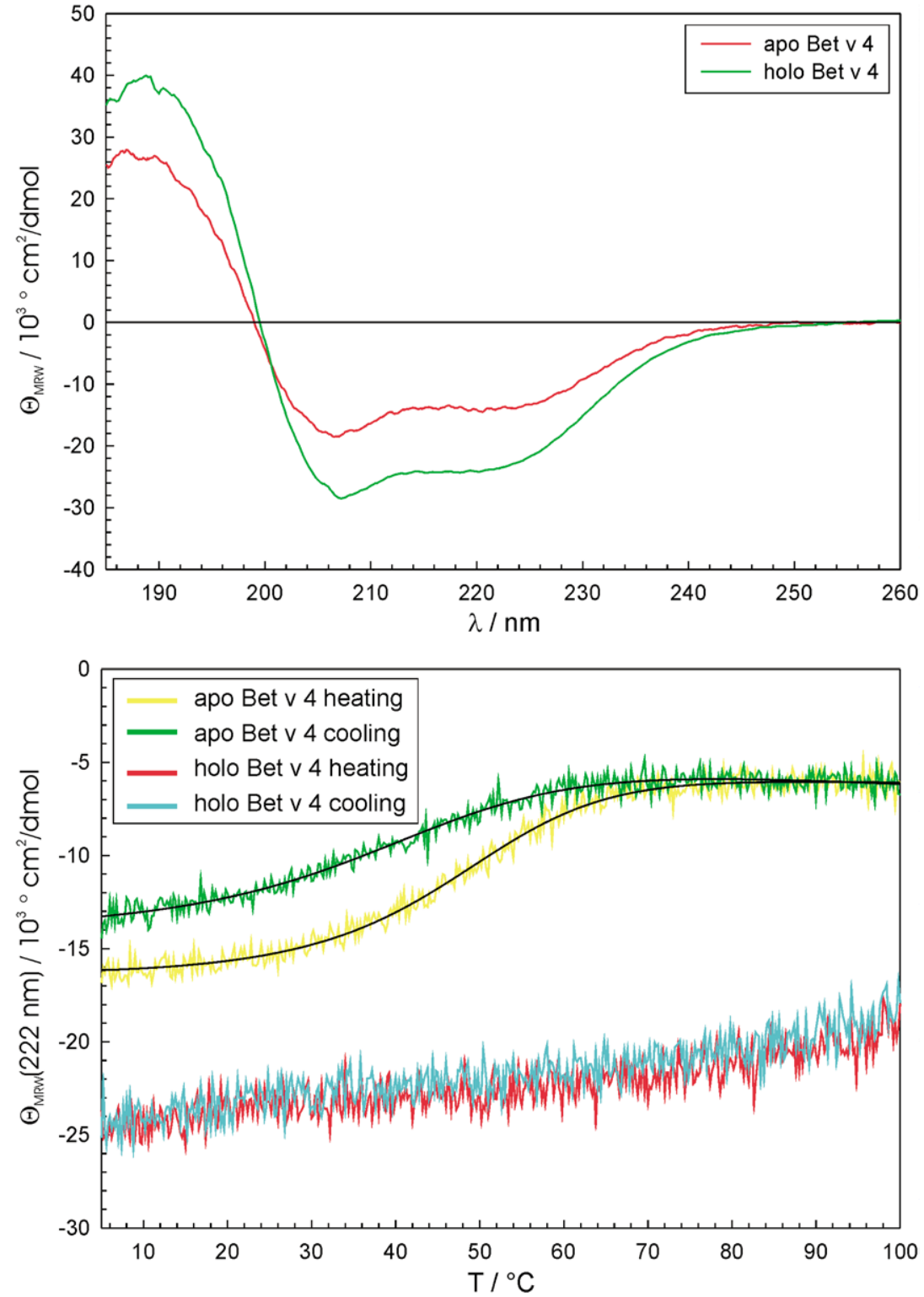

Figure 9. The CD spectra of both apo and holo Bet $\mathrm{v} 4$ are typical for a largely $\alpha$-helical secondary structure (top). The reduction of the apparent helicity upon $\mathrm{Ca}^{2+}$ depletion is completely reversible by addition of $\mathrm{Ca}^{2+}$ (data not shown). The temperature dependence of the CD at $222 \mathrm{~nm}$ (bottom) reveals that the secondary structure of holo Bet $\mathrm{v} 4$ remains stable at all temperatures, whereas apo Bet $\mathrm{v} 4$ undergoes a cooperative thermal transition at midpoints of $t_{\mathrm{m}}=47^{\circ} \mathrm{C}$ (heating) and $t_{\mathrm{m}}=39^{\circ} \mathrm{C}$ (cooling), whose incomplete reversibility indicates some degree of incomplete refolding and/or precipitation. domain-swapped dimers may be of similar allergenicity and explains the clinically observed $\operatorname{IgE}$ cross-reactivity between holo Bet $\mathrm{v} 4$ and holo Phl p 7, although it should be noted that in the immunological characterizations of polcalcins the oligomerization state has rarely been investigated. Within their limited signal-to-noise ratio the NMR spectra of holo Bet $\mathrm{v} 4$ only contain a single set of resonances (Figure 2), which has to be attributed to the monomer. However, since the signal-tonoise ratio of any distinct minor species at low abundance further attenuated by significantly faster transverse relaxation than the monomer cannot necessarily be expected to allow a reliable detection and identification, it remains unclear whether the holo Bet v 4 samples used for NMR spectroscopy contained a small dimeric fraction as well, and only little is known about the small dimeric fraction in the sample used for analytical ultracentrifugation. By analogy to the extremely slow transition between monomeric and domain- swapped dimeric holo calbindin $\mathrm{D}_{9 \mathrm{k}} \mathrm{P} 43 \mathrm{M}$, which proceeds via calcium-free transition states requiring weeks to months and could be trapped by crystallization, ${ }^{43}$ the high kinetic barrier of the monomer-dimer transition in the sedimentation equilibrium experiments indeed suggests domainswapping as the dimerization mechanism for the small fraction of holo Bet $\mathrm{v} 4$. These findings raise the question why $\mathrm{Phl} p$, unlike Bet $\mathrm{v} 4$ and all the other EF-hand proteins and regardless of its calcium-binding state, appears to occur exclusively as a domain-swapped dimer. The fact that both apo and holo Bet v 4 were predominantly monomeric in all samples tested, whereas both apo and holo Phl p 7 were exclusively dimeric under all conditions tested argues against, but cannot rule out, a merely kinetic effect. Unfortunately, none of the three putative reasons put forward to explain the domain-swapping dimerization of apo and holo Phl p $7^{26}$ explains the different behavior of Bet $\mathrm{v} 4$ and Phl p 7, nor 
does the crystal structure of holo Phl p $7^{26}$ support the formation of an intermolecular disulfide bridge by its single cysteine (Figure 1). Again by analogy to holo calbindin $\mathrm{D}_{9 \mathrm{k}} \mathrm{P} 43 \mathrm{M}$, the replacement of the residue corresponding to Pro43 in the linker region between the two EF-hands of Bet $\mathrm{v} 4$ by alanine (Figure 1) might favor the domain-swapping dimerization of holo Phl p 7, although this linker is markedly different in calbindin $\mathrm{D}_{9 \mathrm{k}}$, where the proline under consideration even shows a cis-trans isomerism ${ }^{44}$ not observed in the polcalcins. Alternatively, the shortness of the $\mathrm{NH}_{2}$-terminal helix $\alpha_{1}$ of holo Phl p 7 (Figure 1) might favor its participation in the tight packing at the interface of the domainswapped dimer. ${ }^{26}$ Ultimately, finding the reason for the proneness of Phl p 7 to domain-swapping should allow the design of experiments elucidating the immunological and functional significance of the dimeric form of the polcalcins by deliberately influencing their monomer-dimer equilibrium.

\section{Characterization of the structural transition upon $\mathrm{Ca}^{2+}$ depletion}

The three-dimensional structure of the apo forms of the polcalcins is still completely unknown. The slightly larger hydrodynamic radius of apo Bet $\mathrm{v} 4$ compared to holo Bet $\mathrm{v} 4$ in the NMR translational diffusion and analytical ultracentrifugation measurements (see above) corroborates the results of earlier gel electrophoresis, gel filtration, and size exclusion chromatography experiments on Bet $\mathrm{v} 4$ and other polcalcins. ${ }^{10,18,26}$ Depletion of $\mathrm{Ca}^{2+}$ also causes a reversible reduction of the apparent helicity of Bet v 4 in the CD spectrum (Figure 9), again corroborating the results of earlier studies on Bet v 4 and other polcalcins. ${ }^{10,12,14,19,29}$ Like Aln g $4^{12}$ and Phl p 7,19 the secondary structure of holo Bet $\mathrm{v} 4$ remains stable even at temperatures close to the boiling point of the solvent, whereas apo Bet $\mathrm{v} 4$ is subject to cooperative thermal denaturation at $t_{\mathrm{m}}=47^{\circ} \mathrm{C}$ (Figure 9). In addition, the NMR spectra of apo Bet $\mathrm{v} 4$ no longer exhibit the characteristic shift of several amide resonances in the $\mathrm{Ca}^{2+}$ binding loops of holo Bet v 4 to low field and show markedly poorer chemical shift dispersion (Figure 2). These findings clearly demonstrate that $\mathrm{Ca}^{2+}$ binding to Bet $\mathrm{v} 4$ causes a substantial reversible transition of the tertiary structure, which explains the reduced affinity of the $\operatorname{IgE}$ antibodies of many patients to apo Bet $\mathrm{v} 4$ compared to holo Bet $\mathrm{v} 4 .{ }^{10}$ What is more, the reduction of the apparent helicity and heat stability in the CD spectra as well as the reduction of the chemical shift dispersion of the NMR spectra of Bet $\mathrm{v} 4$ closely resemble the effects of $\mathrm{Ca}^{2+}$ depletion on the CD and NMR spectra of calmodulin, although unlike the apparent helicity in the CD spectrum the actual $\alpha$-helicity of apo calmodulin is similar to holo calmodulin. ${ }^{34,45-47}$ In contrast to EF-hand proteins with a $\mathrm{Ca}^{2+}$ buffering function like parvalbumin and calbindin $\mathrm{D}_{9 \mathrm{k}}{ }^{48}$ EF-hand proteins with a regulatory function like calmodulin ${ }^{34,45-47}$ and troponin $\mathrm{C}$ undergo a substantial rearrangement of the relative orientation of the $\alpha$-helices of each EF-hand from the closed (interhelical angle about $130^{\circ}$ ) to the open (interhelical angle about $100^{\circ}$ ) conformation upon $\mathrm{Ca}^{2+}$ binding, which exposes a large hydrophobic patch on the molecular surface to allow the interaction with the target proteins for signal transduction. ${ }^{30,49}$ Bet v 4 not only shows higher sequence identity to EF-hand proteins with a regulatory than a $\mathrm{Ca}^{2+}$ buffering function (Figure 1), it also undergoes a substantial reversible structural transition upon $\mathrm{Ca}^{2+}$ binding similar to calmodulin (see above) to adopt the canonical two EF-hand assembly in the open conformation (Figure 5; Table 4), thereby exposing a large

Table 4. Comparison of the three-dimensional structure of holo Bet $\mathrm{v} 4$ with selected representative EF-hand proteins

\begin{tabular}{|c|c|c|c|}
\hline & $\begin{array}{l}\text { Backbone atomic RMSD } \\
\text { from the average structure } \\
\text { of holo Bet } v 4^{\mathrm{a}}(\AA)\end{array}$ & $\begin{array}{l}\text { Interhelical angle } \\
\text { of the first } \\
\text { EF-hand }{ }^{\mathbf{b}} \text { (deg.) }\end{array}$ & $\begin{array}{l}\text { Interhelical angle } \\
\text { of the second } \\
\text { EF-hand }{ }^{\mathbf{b}} \text { (deg.) }\end{array}$ \\
\hline holo Bet v $4^{\mathrm{c}}$ & $0.22 \pm 0.08$ (80 residues) & $101.5 \pm 0.9$ & $96.9 \pm 1.0$ \\
\hline apo calmodulin $\mathrm{NH}_{2}{ }^{\mathrm{d}}$ & 3.46 (68 residues) & 131.2 & 131.5 \\
\hline apo calmodulin $\mathrm{COOH}^{\mathrm{e}}$ & 4.31 (65 residues) & 139.0 & 125.6 \\
\hline holo calmodulin $\mathrm{NH}_{2}{ }^{\mathrm{f}}$ & 1.42 (68 residues) & 103.9 & 102.7 \\
\hline holo calmodulin $\mathrm{COOH}^{\mathrm{g}}$ & 1.39 (65 residues) & 104.9 & 103.8 \\
\hline holo troponin $\mathrm{C} \mathrm{NH}_{2}^{\mathrm{h}}$ & 1.37 (68 residues) & 97.3 & 97.7 \\
\hline holo parvalbumin ${ }^{\mathrm{i}}$ & 2.52 (68 residues) & 105.0 & 103.1 \\
\hline holo calbindin $\mathrm{D}_{9 \mathrm{k}}{ }^{\mathrm{j}}$ & 3.82 (67 residues) & 131.0 & 108.7 \\
\hline \multicolumn{4}{|c|}{${ }^{a}$ Backbone atomic RMSD from the average structure of holo Bet $v 4$ (PDB access code $1 \mathrm{H} 4 \mathrm{~B}$ ) over the equivalent residues (Figure 1 ) } \\
\hline \multicolumn{4}{|c|}{$\begin{array}{l}\text { without the unstructured } \mathrm{NH}_{2} \text {-terminal residues } 1-4 \text { and the } \mathrm{COOH} \text {-terminal residues } 73-84 \text { forming the amphipathic helix } \alpha_{5} \text {. } \\
\text { b Calculated using the algorithm of Kuboniwa et al. }{ }^{34}\end{array}$} \\
\hline \multicolumn{4}{|c|}{ c PDB access code $1 \mathrm{H} 4 \mathrm{~B}$; including the COOH-terminal residues $73-84$ forming the amphipathic helix $\alpha_{5}$; values are average value } \\
\hline \multicolumn{4}{|c|}{ over the 25 accepted structures in the form average value \pm standard deviation; $\alpha_{1}: 5-18, \alpha_{2}: 28-38, \alpha_{3}: 43-53, \alpha_{4}: 63-72$} \\
\hline \multicolumn{4}{|c|}{${ }^{\mathrm{d}}$ PDB access code 1F70; model 10; $\alpha_{1}: 6-19, \alpha_{2}: 29-39, \alpha_{3}: 45-55, \alpha_{4}: 65-76$} \\
\hline \multicolumn{4}{|c|}{ e PDB access code $1 F 71 ;$ model $6 ; \alpha_{1}: 82-92, \alpha_{2}: 102-112, \alpha_{3}: 118-128, \alpha_{4}: 138-148}$. \\
\hline \multicolumn{4}{|c|}{ f PDB access code 1J7O; model $2 ; \alpha_{1}: 6-19, \alpha_{2}: 29-39, \alpha_{3}: 45-55, \alpha_{4}: 65-76$} \\
\hline \multicolumn{4}{|c|}{ g PDB access code 1J7P; model $2 ; \alpha_{1}: 82-92, \alpha_{2}: 102-112, \alpha_{3}: 118-128, \alpha_{4}: 138-146}$. \\
\hline \multicolumn{4}{|c|}{ h PDB access code 1AVS; monomer B; $\alpha_{1}: 16-29, \alpha_{2}: 39-48, \alpha_{3}: 55-65, \alpha_{4}: 75-85$} \\
\hline \multicolumn{4}{|c|}{ i PDB access code 5CPV; $\alpha_{1}: 40-50, \alpha_{2}: 60-65, \alpha_{3}: 79-89, \alpha_{4}: 99-107$} \\
\hline \multicolumn{4}{|c|}{ j PDB access code 1B1G; model $1 ; \alpha_{1}: 3-13, \alpha_{2}: 25-35, \alpha_{3}: 46-53, \alpha_{4}: 63-72$} \\
\hline
\end{tabular}


hydrophobic groove which is only partly covered by the polcalcin-specific amphipathic $\mathrm{COOH}$-terminal helix $\alpha_{5}$ (Figure 6). These findings strongly suggest that Bet $\mathrm{v} 4$ serves a regulatory rather than a $\mathrm{Ca}^{2+}$ buffering function. Based on the slightly less negative electrostatic potential of the hydrophobic groove of Bet v 4 (Figure 6) the putative target peptides are expected to be less basic than those of calmodulin, but the identity of the target peptides, the binding stoichiometry, and the exact role of the polcalcin-specific amphipathic $\mathrm{COOH}$-terminal helix $\alpha_{5}$ remain to be determined. Screening of appropriate peptide ligands is therefore under way in our laboratory, as is the determination of the high-resolution three-dimensional structure of apo Bet $\mathrm{v} 4$ to provide a more accurate picture of the reversible structural transition triggered by changes in the calcium concentration, which is so central to both the IgE reactivity and the physiological function of the polcalcins.

\section{Materials and Methods}

\section{Expression and purification of apo and holo Bet v 4}

Overexpression of tagless Bet $\mathrm{v} 4$ was performed in E. coli BL21(DE3) using the expression vector pMW175. ${ }^{10}$ Cultures were grown at $37^{\circ} \mathrm{C}$ to an $A_{600 \mathrm{~nm}}$ of $0.8-0.9$ in LB medium or $\mathrm{M}^{50}$ minimal medium containing $100 \mu \mathrm{g} / \mathrm{ml}$ ampicillin. M9 medium contained the trace element solution TS2, ${ }^{1}, 2 \mathrm{mM} \mathrm{MgSO}_{4}, 10 \mu \mathrm{M} \mathrm{Fe}(\mathrm{III})$ citrate, $0.1 \mathrm{mM} \mathrm{CaCl}_{2}$, and $80 \mathrm{mg} / 1$ glucose. ${ }^{15} \mathrm{~N}$ and ${ }^{13} \mathrm{C} /{ }^{15} \mathrm{~N}$ labeled Bet $\mathrm{v} 4$ was overexpressed in M9 minimal medium with ${ }^{15} \mathrm{NH}_{4} \mathrm{Cl}$ and $\left[{ }^{13} \mathrm{C}_{6}\right]$ glucose. Expression was induced by adding IPTG to a final concentration of $1 \mathrm{mM}$. After induction, cultures were incubated at $37^{\circ} \mathrm{C}$ for three or four hours. The cell pellet was collected by centrifugation and frozen. For the preparation of holo Bet $\mathrm{v} 4$ the cells were dissolved in $20 \mathrm{mM}$ Tris, $2 \mathrm{mM}$ $\mathrm{CaCl}_{2}$ ( $\mathrm{pH} 8.0 ; 4 \mathrm{ml} / \mathrm{g}$ cell pellet) containing one tablet of Protease inhibitor cocktail (Roche, Mannheim, Germany) and disrupted by repeated freezing and thawing. The extract was clarified by centrifugation. The protein was purified from the soluble fraction using reversed phase chromatography (Nucleosil 100-7 C18 column; elution with a constant gradient of $0 \%-56 \%$ acetonitrile in $0.1 \%$ trifluoroacetic acid over 50 minutes at a flow rate of $10 \mathrm{ml} /$ minute). Bet $\mathrm{v} 4$-containing fractions were dried by vacuum concentration. Alternatively, contaminating proteins in the soluble fraction were precipitated by boiling at $90{ }^{\circ} \mathrm{C}$ for ten minutes and removed by filtration, ${ }^{19}$ followed by dialysis against water, lyophilization, redissolving in $5-10 \mathrm{ml} 20 \mathrm{mM}$ Tris, $2 \mathrm{mM} \mathrm{CaCl}_{2}$ ( $\mathrm{pH} 8.0$ ), and subsequent purification using size exclusion chromatography on a HiLoad 26/ 60 Superdex 75 HR column (Amersham Biosciences, Freiburg, Germany). Bet v 4-containing fractions were dialyzed against water and lyophilized. The preparation of apo Bet $\mathrm{v} 4$ was carried out in the presence of $2 \mathrm{mM}$ EDTA instead of $\mathrm{CaCl}_{2}$ in lysis and purification buffers. For NMR studies samples of $0.7-1.5 \mathrm{mM}$ Bet $\mathrm{v} 4$ in up to $20 \mathrm{mM}$ sodium acetate ( $\mathrm{pH} 6.0$ ) with up to $25 \mathrm{mM}$ $\mathrm{CaCl}_{2}$ (holo Bet v 4) or $2 \mathrm{mM}$ EDTA (apo Bet v 4) were prepared.

\section{NMR spectroscopy}

All NMR experiments were performed at $298 \mathrm{~K}$ on Bruker Avance400, DRX600, or DMX750 NMR spectrometers equipped with inverse ${ }^{1} \mathrm{H} /{ }^{13} \mathrm{C} /{ }^{15} \mathrm{~N}\left(/{ }^{31} \mathrm{P}\right)$ triple or quadruple resonance probes with pulsed field gradient capabilities. In addition to homonuclear 2D $\left[{ }^{1} \mathrm{H},{ }^{1} \mathrm{H}\right]$ TOCSY spectra and 2D $\left[{ }^{1} \mathrm{H},{ }^{1} \mathrm{H}\right]$ NOESY spectra (150 ms mixing time) in both $\mathrm{H}_{2} \mathrm{O} /{ }^{2} \mathrm{H}_{2} \mathrm{O}$ (9:1) and ${ }^{2} \mathrm{H}_{2} \mathrm{O}$, the following heteronuclear 2D and 3D NMR experiments were performed on samples of uniformly ${ }^{15} \mathrm{~N}-$ or ${ }^{13} \mathrm{C} /{ }^{15} \mathrm{~N}-$ labeled recombinant Bet $\mathrm{v}$ 4: ${ }^{15} \mathrm{~N}-\mathrm{HSQC}, \mathrm{HNHA},{ }^{15} \mathrm{~N}-$ TOCSY-HSQC, ${ }^{13} \mathrm{C}-\mathrm{CTHSQC}, \mathrm{HNCO}, \mathrm{HNCA}, \mathrm{C}(\mathrm{CO}) \mathrm{NH}$, $\mathrm{H}(\mathrm{C}) \mathrm{CH}-\mathrm{COSY}$, and $(\mathrm{H}) \mathrm{CCH}-\mathrm{COSY}$ for the backbone and aliphatic side-chain resonance assignment, as well as ${ }^{15} \mathrm{~N}$ NOESY-HSQC, $\quad{ }^{13} \mathrm{C}-\mathrm{NOESY}-\mathrm{HSQC}, \quad 3 \mathrm{D} \quad{ }^{15} \mathrm{~N}-\mathrm{HMQC}-$ NOESY-HSQC, and $3 \mathrm{D}{ }^{13} \mathrm{C} /{ }^{15} \mathrm{~N}-\mathrm{HMQC}-\mathrm{NOESY}-\mathrm{HSQC}$ (all $150 \mathrm{~ms}$ mixing time) to collect NOESY data. ${ }^{31,52,53}$ Interresidue ${ }^{3 h} J_{\mathrm{NC}}$ scalar coupling constants across hydrogen bonds were calculated from the intensity ratios between two $\mathrm{H}(\mathrm{N}) \mathrm{CO}$ spectra ${ }^{54}$ with band-selective ${ }^{13} \mathrm{C}^{\alpha}$ decoupling. ${ }^{55}$ Slowly exchanging amide protons still detectable in a series of ${ }^{15} \mathrm{~N}-\mathrm{HSQC}$ spectra one hour, three hours, and 18 hours after dissolving freeze-dried uniformly ${ }^{15} \mathrm{~N}$-labeled Bet $\mathrm{v} 4$ in ${ }^{2} \mathrm{H}_{2} \mathrm{O}$ were also assumed to be involved in hydrogen bonding. $D_{\mathrm{NH}}$ residual dipolar couplings were obtained from the observed doublet splitting of uniformly ${ }^{15} \mathrm{~N}$-labeled Bet v 4 weakly aligned by addition of $11 \mathrm{mg} / \mathrm{ml}$ Pf1 filamentous phage ${ }^{56}$ in ${ }^{15} \mathrm{~N}-\mathrm{IPAP}$ spectra ${ }^{57}$ by subtracting the ${ }^{1} J_{\mathrm{NH}}$ scalar coupling contribution as observed in reference spectra of the unaligned sample. ${ }^{15} \mathrm{~N}$ longitudinal relaxation rates $R_{1}$, transverse relaxation rates $R_{2}$, and $\left\{{ }^{1} \mathrm{H}\right\}^{15} \mathrm{~N}$ NOE values were measured using the pulse sequences of Dayie \& Wagner ${ }^{58}$ and processed as will be described elsewhere (A. E., S. S., P. N. \& P. R., unpublished results). For the determination of $R_{1}$ at $600 \mathrm{MHz}$ proton resonance frequency 13 data points were collected at delays of $6.9 \mathrm{~ms}(4 \times), 752.4 \mathrm{~ms}$ $(4 \times)$, and $1004.4 \mathrm{~ms}(5 \times)$, for $R_{2}$ at $600 \mathrm{MHz} 19$ data points at $17.0 \mathrm{~ms}(5 \times), 101.8 \mathrm{~ms}(4 \times), 169.6 \mathrm{~ms}(5 \times)$, and $254.4 \mathrm{~ms}(5 \times)$, and for $R_{2}$ at $750 \mathrm{MHz} 14$ data points at $17.0 \mathrm{~ms}(5 \times), 101.8 \mathrm{~ms}(3 \times), 169.6 \mathrm{~ms}(3 \times)$, and $254.4 \mathrm{~ms}(3 \times)$. For the determination of $\left\{{ }^{1} \mathrm{H}\right\}^{15} \mathrm{~N}$ NOE values the evolution time increments in the indirect dimension of the spectra with and without proton saturation by applying a train of $120^{\circ}$ high-power pulses for the final three seconds of the relaxation delay of six seconds were recorded in an interleaved manner. Hydrodynamic radii were measured relative to $0.5 \%$ internal dioxane assuming a hydrodynamic radius of $2.12 \AA^{36}$ using pulse gradient stimulated echo longitudinal encode-decode (PG-SLED) translational diffusion experiments ${ }^{59}$ in ${ }^{2} \mathrm{H}_{2} \mathrm{O}$ with weak presaturation of the $\mathrm{H}^{2} \mathrm{HO}$ resonance. $D_{\mathrm{NH}}$ residual dipolar couplings and $\left\{{ }^{1} \mathrm{H}\right\}^{15} \mathrm{~N}$ NOE values at $600 \mathrm{MHz}$ were averaged over three independent datasets, $\left\{{ }^{1} \mathrm{H}\right\}^{15} \mathrm{~N}$ NOE values at $750 \mathrm{MHz}$ over two, and hydrodynamic radii over five. The NMR data were processed using NMRPipe ${ }^{60}$ as well as in-house written software and analyzed with the program packages NMRView ${ }^{61}$ and NDEE (SpinUp Inc., Dortmund, Germany). ${ }^{1} \mathrm{H}$ chemical shifts were referenced with respect to external DSS in ${ }^{2} \mathrm{H}_{2} \mathrm{O},{ }^{13} \mathrm{C}$ and ${ }^{15} \mathrm{~N}$ chemical shifts were referenced indirectly. ${ }^{62}$

\section{Sequence-specific resonance assignments and scalar coupling constants}

Sequence-specific backbone amide resonance assignments by the standard procedure ${ }^{63}$ based on the 
${ }^{15} \mathrm{~N}-\mathrm{TOCSY}-\mathrm{HSQC},{ }^{15} \mathrm{~N}-\mathrm{NOESY}-\mathrm{HSQC}$, and $3 \mathrm{D}{ }^{15} \mathrm{~N}-\mathrm{HMQC}-$ NOESY-HSQC spectra were supplemented by the $\mathrm{HNCO}, \mathrm{HNCA}$, and $\mathrm{C}(\mathrm{CO}) \mathrm{NH}$ spectra. Aliphatic sidechain resonance assignments were obtained from the ${ }^{15} \mathrm{~N}$-TOCSY-HSQC, $\mathrm{H}(\mathrm{C}) \mathrm{CH}-\mathrm{COSY}$, and $(\mathrm{H}) \mathrm{CCH}-\mathrm{COSY}$ spectra, aromatic side-chain resonance assignments from the ${ }^{15} \mathrm{~N}$-NOESY-HSQC, ${ }^{13} \mathrm{C}$-NOESY-HSQC, $2 \mathrm{D}\left[{ }^{1} \mathrm{H}\right.$, $\left.{ }^{1} \mathrm{H}\right] \mathrm{TOCSY}$, and $2 \mathrm{D}\left[{ }^{1} \mathrm{H},{ }^{1} \mathrm{H}\right]$ NOESY spectra, and ${ }^{3} J_{\mathrm{HNH} \alpha}$ scalar coupling constants from the HNHA spectrum.

\section{Structure calculation}

NOE cross-peaks identified in the 2D and 3D NOESY spectra in an iterative procedure as well as hydrogen bonds and ${ }^{3} \int_{\mathrm{HNH} \alpha}$ scalar coupling constants were converted into distance and $\Phi$ backbone torsion angle restraints, respectively, as described. ${ }^{6}$ Together with a harmonic potential ${ }^{64}$ for those $D_{\mathrm{NH}}$ residual dipolar coupling constants with $S^{2}>0.70$ in the RSDM (Figure 3), using estimates from the powder pattern ${ }^{65}$ of $-12.7 \mathrm{~Hz}$ and 0.37 for the axial and rhombic component of the alignment tensor, respectively, these experimental restraints served as an input for the calculation of 90 structures using restrained molecular dynamics according to a three-stage simulated annealing protocol ${ }^{66}$ using floating assignment of prochiral groups ${ }^{67}$ with the NIH version $1.2 .1^{68}$ of X-PLOR $3.851^{69}$ as described. ${ }^{6}$ To reduce the high bond angle energy caused by inconsistencies in the original bond geometry parameter file parallhdg.pro, ideal bond angles at $\mathrm{C}^{\alpha}$ were reset to an ideal tetrahedron, ideal bond lengths and angles between the heavy atoms of proline set to standard values, ${ }^{70}$ and ideal bond angles of proline involving one hydrogen atom adapted in steps of $0.5^{\circ}$ to minimize root mean square bond angle deviations for the eight proline residues of the lowest energy structure of Pru av $1^{6}$ after 1000 steps of Powell minimization ${ }^{71}$ without introducing new atom types. Ideal bond lengths, bond angles, and improper angles between the calcium ions and its protein oxygen ligands were determined from a protoype obtained by averaging the atomic coordinates of the four $\mathrm{NH}_{2}$-terminal calcium clusters of two crystal structures of Paramecium tetraurelia calmodulin ${ }^{72,73}$ (atomic RMSD from this protoype $0.123( \pm 0.021) \AA$ ). The Gaussian conformational database potential ${ }^{74}$ with a cutoff of 10.0 standard deviations, ${ }^{75}$ a potential for direct refinement against the ${ }^{13} \mathrm{C}^{\alpha}$ and ${ }^{13} \mathrm{C}^{\beta}$ chemical shift combinations ${ }^{76}$ of the non-terminal residues except for glycine with a correction for residues followed by proline, ${ }^{77}$ and a potential restraining the radius of gyration ${ }^{78}$ of residues 5-84 to $11.7 \AA$ were included in the target function in order to improve the stereochemical properties, the agreement with ${ }^{13} \mathrm{C}$ chemical shifts, and the packing of the structures, respectively. The 25 structures showing the lowest energy values (excluding conformational database, ${ }^{13} \mathrm{C}$ chemical shift, and radius of gyration potential) were selected for further characterization using the $\mathrm{NIH}$ version $1.2 .1^{68}$ of X-PLOR $3.851^{69}$ and PROCHECK 3.4. ${ }^{32}$

\section{Complete cross-validation}

For complete cross-validation ${ }^{33}$ the NOE distance restraints were randomly partitioned into ten test sets of roughly equal size (between 127 and 155). Ten sets of 60 structures were calculated, each of the sets with one of the distance restraint test sets left out. For those 21 structures of each set showing the lowest energy values, the
RMSDs from the distance restraints not used for their calculation were determined after assigning the restraints from the nine working sets a relative weight of $10 \mathrm{com}$ pared to those from the test set in order to prioritize them during floating assignment of prochiral groups.

\section{NMR relaxation data analysis}

Relaxation rates were obtained by least-squares fitting of monoexponential decays to the peak heights extracted with NMRView 5.0.4 ${ }^{61}$ using the program Curvefit (Palmer, A. G., unpublished), with error estimation by the jackknife procedure. ${ }^{15} \mathrm{~N}$ relaxation data at $600 \mathrm{MHz}$ were interpreted by $\mathrm{RSDM}^{79}$ followed by calculation of generalized order parameters $S^{2}$ as described by Bracken et al. ${ }^{80}$ using residual overall tumbling autocorrelation times. Residues with large internal motions on the subnanosecond time-scale as indicated by low $\left\{{ }^{1} \mathrm{H}\right\}^{15} \mathrm{~N}$ NOE values or involved in exchange processes as indicated by elevated transverse relaxation rates $R_{2}$ especially at $750 \mathrm{MHz}$ in combination with normal longitudinal relaxation rates $R_{1}$ were considered to possess significantly increased internal mobility. ${ }^{81}$ For these mobile residues the average value of the overall tumbling autocorrelation times of the rigid residues of 5.74( \pm 0.38$)$ ns was used instead of their own residual values for the calculation of the generalized order parameter $S^{2}{ }^{80}$ These mobile residues were also excluded from the calculation of the rotational diffusion tensor based on the lowest energy structure of holo Bet v 4 using Tensor $2.0^{82}$ with the default parameters.

\section{Analytical ultracentrifugation}

Sedimentation equilibrium and velocity experiments were carried out on an Optima XL-A/XL-I analytical ultracentrifuge (Beckman Coulter, Fullerton, CA, USA) equipped with both absorbance and interference optical detection systems using a Beckman An-60 Ti rotor with cells containing sapphire windows and titanium double-sector centerpieces (path length $1.2 \mathrm{~cm}$; Nanolytics $\mathrm{GmbH}$, Dallgow, Germany). Prior to centrifugation, holo and apo Bet $\mathrm{v} 4$ were dialyzed against $50 \mathrm{mM}$ sodium acetate, $2 \mathrm{mM} \mathrm{CaCl}, 50 \mathrm{mM} \mathrm{NaCl}$ (pH 6.0) and $50 \mathrm{mM}$ sodium acetate, $1 \mathrm{mM}$ EDTA, $50 \mathrm{mM}$ $\mathrm{NaCl}(\mathrm{pH} 6.0)$, respectively. The protein concentration was determined via the BCA method. ${ }^{83}$ The partial specific volume $(0.7288 \mathrm{l} / \mathrm{g})$ and molecular weight for apo and holo Bet v 4 (9316 Da and $9396 \mathrm{Da}$, respectively) based on the amino acid composition as well as the density of the buffers were calculated using the program Sednterp. ${ }^{84}$ In the experiments using interference optics 3.33 fringes were taken as equal to $1 \mathrm{mg} / \mathrm{ml}$ protein. For sedimentation velocity experiments, samples (200$250 \mu \mathrm{l})$ and reference $(210-260 \mu \mathrm{l})$ solutions were loaded into cells at initial total concentrations between $120 \mu \mathrm{M}$ and $900 \mu \mathrm{M}$. Experiments were conducted at $20{ }^{\circ} \mathrm{C}$ at a rotor speed of $60,000 \mathrm{rpm}$ using sapphire windows. Interference fringe displacement data were collected at time intervals of 30 seconds without averaging. Sedimentation velocity data was fitted either by a continuous size distribution $c(s)$ or a non-interacting discrete species model and $c(s)$ subsequently converted into a molar mass distribution $c(M)^{37-39}$ using the program Sedfit $8.52 \uparrow$. The diffusion coefficient $D(s)$ was estimated based

$\dagger$ http://www.analyticalultracentrifugation.com 
on the known partial specific volume of the protein and on the best-fit weight-average frictional ratio $f / f_{0}$ obtained from fitting the continuous size distribution. ${ }^{37}$ Protein hydration was assumed to be $30 \%(\mathrm{w} / \mathrm{w}){ }^{85}$ For the sedimentation equilibrium experiments the cells were filled with sample $(130-150 \mathrm{ml})$ and reference $(140-160 \mathrm{ml})$ solutions at loading concentrations between $120 \mu \mathrm{M}$ and $900 \mu \mathrm{M}$.

Sedimentation equilibrium was attained at 24 hours at a rotor temperature of $20^{\circ} \mathrm{C}$ and rotor speeds of $16,000 \mathrm{rpm}, 20,000 \mathrm{rpm}$, and $24,000 \mathrm{rpm}$, respectively. Interferometric patterns recorded with pure water in the cell at appropriate speeds were used to correct for radius-dependent fluctuation in Rayleigh response across the cell. ${ }^{86}$ Global data analysis of several datasets obtained at different loading concentrations and rotor speeds was performed using the Beckman XL-A/XL-I data analysis software 4.0 (Beckman Coulter, Fullerton, CA, USA) for fitting the self-association models and the program Sedfit 8.5 for the non-interacting discrete species model. Estimates of the weight-average molar masses $M_{\mathrm{r}}$ were obtained from the least-squares fits based on the Boltzmann distributions of ideal species in the centrifugal field:

$$
S(r)=S\left(r_{0}\right) \exp \left(\sigma\left(r^{2}-r_{0}^{2}\right)\right)+E
$$

where $S(r)$ is the experimentally observed concentration signal in fringes at radius $r, S\left(r_{0}\right)$ is the concentration signal at the reference radius $r_{0}, \sigma=M_{\mathrm{r}}(1-v \rho)\left(\omega^{2} / 2 R T\right)$, $M_{\mathrm{r}}$ the weight average molar mass of the monomer, $v$ the partial specific volume of the solute, $\rho$ the solvent density, $\omega$ the rotor angular velocity, $R$ the gas constant, $T$ the temperature, and $E$ the baseline offset, and on models found in the data analysis software involving multiple species. ${ }^{87,88}$

\section{CD spectroscopy}

CD spectra of self-buffered $1.2 \mathrm{mM}$ holo Bet $\mathrm{v} 4$ in $25 \mathrm{mM} \mathrm{CaCl}_{2}$ and $1.0 \mathrm{mM}$ apo Bet $\mathrm{v} 4$ (pH 6.0) from $185 \mathrm{~nm}$ to $260 \mathrm{~nm}$ were recorded on a Jasco J-810 Spectropolarimeter with a CDF-426S temperature control element using a step width of $0.2 \mathrm{~nm}$, a band width of $1 \mathrm{~nm}$, and a scanning speed of $50 \mathrm{~nm} /$ minute in cuvettes with a light path of $10 \mu \mathrm{m}$ (Hellma, Müllheim, Germany) at a temperature of $22{ }^{\circ} \mathrm{C}$. To increase the signal-to-noise ratio eight scans were accumulated. The residue ellipticity $\Theta_{\mathrm{MRW}}$ was calculated from the measured ellipticity $\Theta$ according to:

$$
\Theta_{\mathrm{MRW}}=\frac{\Theta}{c d N}
$$

where $c$ denotes the protein concentration, $d$ the light path, and $N$ the number of residues. ${ }^{89}$ The temperature dependence of the CD at $222 \mathrm{~nm}$ of $20 \mu \mathrm{M}$ holo Bet v 4 in $1 \mathrm{mM} \mathrm{CaCl}_{2}, 5 \mathrm{mM}$ sodium acetate ( $\mathrm{pH}$ 6.0) and of $20 \mu \mathrm{M}$ apo Bet $\mathrm{v} 4$ in $0.5 \mathrm{mM}$ EGTA, $5 \mathrm{mM}$ sodium acetate $(\mathrm{pH}$ 6.0) was measured in a cuvette with a light path of $1 \mathrm{~mm}$ (Hellma, Müllheim, Germany) at heating and cooling rates of $1 \mathrm{deg} . \mathrm{C} /$ minute, allowing the calculation of the midpoint of the thermal transitions $t_{\mathrm{m}}$ by non-linear least-squares fitting. ${ }^{90}$

\section{Data bank accession numbers}

Together with the experimental restraints the atomic coordinates of the set of 25 structures have been deposited with the PDB (access code: $1 \mathrm{H} 4 \mathrm{~B}$ ). ${ }^{1} \mathrm{H},{ }^{13} \mathrm{C}$, and ${ }^{15} \mathrm{~N}$ chemical shifts, ${ }^{3} J_{\mathrm{HNH} \alpha}$ scalar coupling constants, and ${ }^{15} \mathrm{~N}$ relaxation data of holo Bet $\mathrm{v} 4$ have been deposited with the BioMagResBank (access code: 5490).

\section{Acknowledgements}

We thank M. Zeeb \& Dr J. Balbach for assistance with the NMR relaxation and diffusion experiments and P. Deuerling, N. Herz, \& R. Hofmann for expert technical assistance. P.N. gratefully acknowledges a fellowship from the Fonds des Verbandes der Chemischen Industrie in cooperation with the Bundesministerium für Bildung und Forschung (BMBF). This work was supported by grants from the Deutsche Forschungsgemeinschaft (Ro617/11-1) and the BMBF.

\section{References}

1. Kuby, J. (1992). Immunology, Freeman, New York pp. 359-372.

2. Breiteneder, H., Pettenburger, K., Bito, A., Valenta, R., Kraft, D., Rumpold, H. et al. (1989). The gene coding for the major birch pollen allergen BetvI, is highly homologous to a pea disease resistance response gene. EMBO J. 8, 1935-1938.

3. Gajhede, M., Osmark, P., Poulsen, F. M., Ipsen, H., Larsen, J. N., van Neerven, R. J. J. et al. (1996). X-ray and NMR structure of Bet $\mathrm{v} 1$, the origin of birch pollen allergy. Nature Struct. Biol. 3, 1040-1045.

4. Schweimer, K., Sticht, H., Nerkamp, J., Boehm, M., Breitenbach, M., Vieths, S. \& Rösch, P. (1999). NMR spectroscopy reveals common structural features of the birch pollen allergen Bet $\mathrm{v} 1$ and the cherry allergen Pru a 1. Appl. Magn. Reson. 17, 449-464.

5. Neudecker, P., Schweimer, K., Nerkamp, J., Boehm, M., Scheurer, S., Vieths, S. et al. (2000). Sequencespecific ${ }^{1} \mathrm{H},{ }^{13} \mathrm{C}$ and ${ }^{15} \mathrm{~N}$ resonance assignments of the major cherry allergen Pru a 1. J. Biomol. NMR, 18, 71-72.

6. Neudecker, P., Schweimer, K., Nerkamp, J., Scheurer, S., Vieths, S., Sticht, H. \& Rösch, P. (2001). Allergic cross-reactivity made visible. Solution structure of the major cherry allergen Pru av 1. J. Biol. Chem. 276, 22756-22763.

7. Neudecker, P., Lehmann, K. \& Rösch, P. (2003). Sequence-specific ${ }^{1} \mathrm{H},{ }^{13} \mathrm{C}$ and ${ }^{15} \mathrm{~N}$ resonance assignments of SAM22, an allergenic stress-induced protein from soy bean. J. Biomol. NMR, 26, 191-192.

8. Neudecker, P., Lehmann, K., Nerkamp, J., Haase, T., Wangorsch, A., Fötisch, K. et al. (2003). Mutational epitope analysis of Pru av 1 and Api g 1, the major allergens of cherry and celery: correlating $\operatorname{IgE}$ reactivity with three-dimensional structure. Biochem. J. 376, 97-107.

9. Vieths, S., Scheurer, S. \& Ballmer-Weber, B. (2002). Current understanding of cross-reactivity of food allergens and pollen. Ann. N. Y. Acad. Sci. 964, 47-68.

10. Engel, E., Richter, K., Obermeyer, G., Briza, P., Kungl, A. J., Simon, B. et al. (1997). Immunological and biological properties of Bet $\mathrm{v} 4$, a novel birch pollen allergen with two ef-hand calcium-binding domains. J. Biol. Chem. 272, 28630-28637.

11. Twardosz, A., Hayek, B., Seiberler, S., Vangelista, L., 
Elfman, L. \& Grönlund, H. (1997). Molecular characterization, expression in Escherichia coli, and epitope analysis of a two EF-hand calcium-binding birch pollen allergen, Bet v 4. Biochem. Biophys. Res. Commun. 239, 197-204.

12. Hayek, B., Vangelista, L., Pastore, A., Sperr, W. R., Valent, P., Vrtala, S. et al. (1998). Molecular and immunologic characterization of a highly cross-reactive two EF-hand calcium-binding alder pollen allergen, Aln g 4: structural basis for calcium-modulated IgE recognition. J. Immunol. 161, 7031-7039.

13. Batanero, E., Villalba, M., Ledesma, A., Puente, J. X. \& Rodríguez, R. (1996). Ole e 3, an olive-tree allergen, belongs to a widespread family of pollen proteins. Eur. J. Biochem. 241, 772-778.

14. Ledesma, A., Villalba, M., Batanero, E. \& Rodríguez, R. (1998). Molecular cloning and expression of active Ole e 3, a major allergen from olive-tree pollen and member of a novel family of $\mathrm{Ca}^{2+}$-binding proteins (polcalcins) involved in allergy. Eur. J. Biochem. 258, 454-459.

15. Toriyama, K., Okada, T., Watanabe, M., Ide, T., Ashida, T., Xu, H. \& Singh, M. B. (1995). A cDNA clone encoding an IgE-binding protein from Brassica anther has significant sequence similarity to $\mathrm{Ca}^{2+}$ binding proteins. Plant Mol. Biol. 29, 1157-1165.

16. Okada, T., Swoboda, I., Bhalla, P. L., Toriyama, K. \& Singh, M. B. (1998). Engineering of hypoallergenic mutants of the Brassica pollen allergen, Bra $r$, for immunotherapy. FEBS Letters, 434, 255-260.

17. Focke, M., Hemmer, W., Hayek, B., Götz, M. \& Jarisch, R. (1998). Identification of allergens in oilseed rape (Brassica napus) pollen. Int. Arch. Allergy Immunol. 117, 105-112.

18. Rozwadowski, K., Zhao, R., Jackman, L., Huebert, T., Burkhart, W. E., Hemmingsen, S. M. et al. (1999). Characterization and immunolocalization of a cytosolic calcium-binding protein from Brassica napus and Arabidopsis pollen. Plant Physiol. 120, 787-797.

19. Niederberger, V., Hayek, B., Vrtala, S., Laffer, S., Twardosz, A., Vangelista, L. et al. (1999). Calciumdependent immunoglobulin $\mathrm{E}$ recognition of the apo- and calcium-bound form of a cross-reactive two EF-hand timothy grass pollen allergen, Phl p 7. FASEB J. 13, 843-856.

20. Smith, P. M., Xu, H., Swoboda, I. \& Singh, M. B. (1997). Identification of a Ca ${ }^{2+}$ binding protein as a new Bermuda grass pollen allergen Cyn d 7: $\operatorname{IgE}$ cross-reactivity with oilseed rape pollen allergen Bra r 1. Int. Arch. Allergy Immunol. 114, 265-271.

21. Suphioglu, C., Ferreira, F. \& Knox, R. B. (1997). Molecular cloning and immunological characterisation of Cyn d 7, a novel calcium-binding allergen from Bermuda grass pollen. FEBS Letters, 402, 167-172.

22. King, T. P., Hoffman, D., Løwenstein, H., Marsh, D. G., Platts-Mills, T. A. E. \& Thomas, W. (1994). Allergen nomenclature. Int. Arch. Allergy Immunol. $105,224-233$.

23. Valenta, R., Hayek, B., Seiberler, S., Bugajska-Schretter, A., Niederberger, V., Twardosz, A. et al. (1998). Calcium-binding allergens: from plants to man. Int. Arch. Allergy Immunol. 117, 160-166.

24. Okada, T., Zhang, Z., Russell, S. D. \& Toriyama, K. (1999). Localization of the $\mathrm{Ca}^{2+}$-binding protein, Bra $\mathrm{r} 1$, in anthers and pollen tubes. Plant Cell Physiol. 40, 1243-1252.

25. Okada, T., Sasaki, Y., Ohta, R., Onozuka, N. \& Toriyama, K. (2000). Expression of Bra $r 1$ gene in transgenic tobacco and Bra $r 1$ promoter activity in pollen of various plant species. Plant Cell Physiol. 41, 757-766.

26. Verdino, P., Westritschnig, K., Valenta, R. \& Keller, W. (2002). The cross-reactive calcium-binding pollen allergen, $\mathrm{Phl} \mathrm{p} 7$, reveals a novel dimer assembly. EMBO J. 21, 5007-5016.

27. Grote, M., Hayek, B., Reichelt, R., Kraft, D. \& Valenta, R. (1999). Immunogold electron microscopic localization of the cross-reactive two-EF-Hand calcium-binding birch pollen allergen Bet $\mathrm{v} 4$ in dry and rehydrated birch pollen. Int. Arch. Allergy Immunol. 120, 287-294.

28. Tinghino, R., Twardosz, A., Barletta, B., Puggioni, E. M. R., Iacovacci, P., Butteroni, C. et al. (2002). Molecular, structural, and immunologic relationships between different families of recombinant calciumbinding pollen allergens. J. Allergy Clin. Immunol. 109, 314-320.

29. Ledesma, A., González, E., Pascual, C. Y., Quiralte, J., Villalba, M. \& Rodríguez, R. (2002). Are Ca ${ }^{2+}$-binding motifs involved in the immunoglobulin E-binding of allergens? Olive pollen allergens as model of study. Clin. Expt. Allergy, 32, 1476-1483.

30. Lewit-Bentley, A. \& Réty, S. (2000). EF-hand calciumbinding proteins. Curr. Opin. Struct. Biol. 10, 637-643.

31. Ikura, M., Kay, L. E. \& Bax, A. (1990). A novel approach for sequential assignment of ${ }^{1} \mathrm{H},{ }^{13} \mathrm{C}$, and ${ }^{15} \mathrm{~N}$ spectra of larger proteins: heteronuclear tripleresonance three-dimensional NMR spectroscopy. Application to calmodulin. Biochemistry, 29, 4659-4667.

32. Laskowski, R. A., MacArthur, M. W., Moss, D. S. \& Thornton, J. M. (1993). PROCHECK: a program to check the stereochemical quality of protein structures. J. Appl. Crystallog. 26, 283-291.

33. Brünger, A. T., Clore, G. M., Gronenborn, A. M., Saffrich, R. \& Nilges, M. (1993). Assessing the quality of solution nuclear magnetic resonance structures by complete cross-validation. Science, 261, 328-331.

34. Kuboniwa, H., Tjandra, N., Grzesiek, S., Ren, H., Klee, C. B. \& Bax, A. (1995). Solution structure of calcium-free calmodulin. Nature Struct. Biol. 2, 768-776.

35. Woessner, D. E. (1962). Nuclear spin relaxation in ellipsoids undergoing rotational Brownian motion. J. Chem. Phys. 37, 647-654.

36. Wilkins, D. K., Grimshaw, S. B., Receveur, V., Dobson, C. M., Jones, J. A. \& Smith, L. J. (1999). Hydrodynamic radii of native and denatured proteins measured by pulse field gradient NMR techniques. Biochemistry, 38, 16424-16431.

37. Schuck, P. (2000). Size-distribution analysis of macromolecules by sedimentation velocity ultracentrifugation and Lamm equation modeling. Biophys. J. 78, 1606-1619.

38. Schuck, P., Perugini, M. A., Gonzales, N. R., Howlett, G. J. \& Schubert, D. (2002). Size-distribution analysis of proteins by analytical ultracentrifugation: strategies and application to model systems. Biophys. J. 82, 1096-1111.

39. Lauber, T., Nourse, A., Schulz, A. \& Marx, U. C. (2002). Native and recombinant proguanylin feature identical biophysical properties and are monomeric in solution. Biochemistry, 41, 14602-14612.

40. Perrin, F. (1934). Mouvement brownien d'un ellipsoïde (I). Dispersion diélectrique pour des molécules ellipsoïdales. J. Phys. Radium, 5, 497-511.

41. Perrin, F. (1936). Mouvement brownien d'un ellipsoïde (II). Rotation libre et dépolarisation des 
fluorescences. Translation et diffusion de molécules ellipsoïdales. J. Phys. Radium, 7, 1-11.

42. Cho, C. H., Urquidi, J., Singh, S. \& Robinson, G. W. (1999). Thermal offset viscosities of liquid $\mathrm{H}_{2} \mathrm{O}, \mathrm{D}_{2} \mathrm{O}$, and $\mathrm{T}_{2} \mathrm{O}$. J. Phys. Chem. B103, 1991-1994.

43. Håkansson, M., Svensson, A., Fast, J. \& Linse, S (2001). An extended hydrophobic core induces EFhand swapping. Protein Sci. 10, 927-933.

44. Kördel, J., Skelton, N. J., Akke, M. \& Chazin, W. J. (1993). High-resolution solution structure of calcium-loaded calbindin $\mathrm{D}_{9 \mathrm{k}}$. J. Mol. Biol. 231, 711-734.

45. Tjandra, N., Kuboniwa, H., Ren, H. \& Bax, A. (1995). Rotational dynamics of calcium-free calmodulin studied by ${ }^{15} \mathrm{~N}-\mathrm{NMR}$ relaxation measurements. Eur. J. Biochem. 230, 1014-1024.

46. Zhang, M., Tanaka, T. \& Ikura, M. (1995). Calciuminduced conformational transition revealed by the solution structure of apo calmodulin. Nature Struct. Biol. 9, 758-767.

47. Finn, B. E., Evenäs, J., Drakenberg, T., Waltho, J. P., Thulin, E. \& Forsén, S. (1995). Calcium-induced structural changes and domain autonomy in calmodulin. Nature Struct. Biol. 9, 777-783.

48. Skelton, N. J., Kördel, J., Akke, M., Forsén, S. \& Chazin, W. (1994). Signal transduction versus buffering activity in $\mathrm{Ca}^{2+}$-binding proteins. Nature Struct. Biol. 1, 239-245.

49. Hoeflich, K. P. \& Ikura, M. (2002). Calmodulin in action: diversity in target recognition and activation mechanisms. Cell, 108, 739-742.

50. Sambrook, J., Fritsch, E. F. \& Maniatis, T. (1989). Mol ecular Cloning. A Laboratory Manual, Cold Spring Harbor Laboratory Press, Cold Spring Harbor, New York.

51. Meyer, O. \& Schlegel, H. G. (1983). Biology of aerobic carbon monoxide-oxidizing bacteria. Annu. Rev. Microbiol. 37, 277-310.

52. Bax, A. \& Grzesiek, S. (1993). Methodological advances in protein NMR. Acc. Chem. Res. 26, 131-138.

53. Sattler, M., Schleucher, J. \& Griesinger, C. (1999). Heteronuclear multidimensional NMR experiments for the structure determination of proteins in solution employing pulsed field gradients. Prog. NMR Spectrosc. 34, 93-158.

54. Cordier, F. \& Grzesiek, S. (1999). Direct observation of hydrogen bonds in proteins by interresidue ${ }^{3 \mathrm{~h}} \mathrm{~J}_{\mathrm{NC}}$ scalar couplings. J. Am. Chem. Soc. 121, 1601-1602.

55. Liu, A., Hu, W., Majumdar, A., Rosen, M. K. \& Patel, D. J. (2000). Detection of very weak side chain-main chain hydrogen bonding interactions in mediumsize ${ }^{13} \mathrm{C} /{ }^{15} \mathrm{~N}$-labeled proteins by sensitivity-enhanced NMR spectroscopy. J. Biomol. NMR, 17, 79-82.

56. Hansen, M. R., Mueller, L. \& Pardi, A. (1998). Tunable alignment of macromolecules by filamentous phage yields dipolar coupling interactions. Nature Struct. Biol. 5, 1065-1074.

57. Ottiger, M., Delaglio, F. \& Bax, A. (1998). Measurement of $J$ and dipolar couplings from simplified two-dimensional NMR Spectra. J. Magn. Reson. 131, 373-378

58. Dayie, K. T. \& Wagner, G. (1994). Relaxation-rate measurements for ${ }^{15} \mathrm{~N}-{ }^{1} \mathrm{H}$ groups with pulsed-field gradients and preservation of coherence pathways. J. Magn. Reson. A111, 121-126.

59. Jones, J. A., Wilkins, D. K., Smith, L. J. \& Dobson, C. M. (1997). Characterisation of protein unfolding by NMR diffusion measurements. J. Biomol. NMR, 10, 199-203.

60. Delaglio, F., Grzesiek, S., Vuister, G. W., Zhu, G.,
Pfeifer, J. \& Bax, A. (1995). NMRPipe: a multidimensional spectral processing system based on UNIX pipes. J. Biomol. NMR, 6, 277-293.

61. Johnson, B. A. \& Blevins, R. A. (1994). NMRView: a computer program for the visualization and analysis of NMR data. J. Biomol. NMR, 4, 603-614.

62. Markley, J. L., Bax, A., Arata, Y., Hilbers, C. W., Kaptein, R., Sykes, B. D. et al. (1998). Recommendations for the presentation of NMR structures of proteins and nucleic acids (IUPAC recommendations 1998). Pure Appl. Chem. 70, 117-142.

63. Wüthrich, K. (1986). NMR of Proteins and Nucleic Acids, Wiley, New York.

64. Tjandra, N., Omichinski, J. G., Gronenborn, A. M., Clore, G. M. \& Bax, A. (1997). Use of dipolar ${ }^{1} \mathrm{H}-{ }^{15} \mathrm{~N}$ and ${ }^{1} \mathrm{H}-{ }^{13} \mathrm{C}$ couplings in the structure determination of magnetically oriented macromolecules in solution. Nature Struct. Biol. 4, 732-738.

65. Clore, G. M., Gronenborn, A. M. \& Bax, A. (1998). A robust method for determining the magnitude of the fully asymmetric alignment tensor of oriented macromolecules in the absence of structural information. J. Magn. Reson. 133, 216-221.

66. Kharrat, A., Macias, M. J., Gibson, T. J., Nilges, M. \& Pastore, A. (1995). Structure of the dsRNA binding domain of E. coli RNase III. EMBO J. 14, 3572-3584.

67. Holak, T. A., Nilges, M. \& Oschkinat, H. (1989). Improved strategies for the determination of protein structures from NMR data: the solution structure of acyl carrier protein. FEBS Letters, 242, 218-224.

68. Schwieters, C. D., Kuszewski, J. J., Tjandra, N. \& Clore, G. M. (2003). The Xplor-NIH NMR molecular structure determination package. J. Magn. Reson. $160,65-73$.

69. Brünger, A. T. (1992). X-PLOR Version 3.1. A System for X-ray Crystallography and NMR, Yale University Press, New Haven.

70. Engh, R. A. \& Huber, R. (1991). Accurate bond and angle parameters for $\mathrm{X}$-ray protein structure refinement. Acta Crystallog. sect. A, 47, 392-400.

71. Powell, M. J. D. (1977). Restart procedures for the conjugate gradient method. Math. Progr. 12, 241-254.

72. Rao, S. T., Wu, S., Satyshur, K. A., Ling, K.-Y., Kung, C. \& Sundaralingam, M. (1993). Structure of Paramecium tetraurelia calmodulin at $1.8 \AA$ resolution. Protein Sci. 2, 436-447.

73. Ban, C. B., Ramakrishnan, B., Ling, K.-Y., Kung, C. \& Sundaralingam, M. (1994). Structure of the recombinant Paramecium tetraurelia calmodulin at $1.68 \AA$ resolution. Acta Crystallog. sect. D, 50, 50-63.

74. Kuszewski, J. J. \& Clore, G. M. (2000). Sources of and solutions to problems in the refinement of protein NMR structures against torsion angle potentials of mean force. J. Magn. Reson. 146, 249-254.

75. Neudecker, P., Sticht, H. \& Rösch, P. (2001). Improving the efficiency of the Gaussian conformational database potential for the refinement of protein and nucleic acid structures. J. Biomol. NMR, 21, 373-375.

76. Kuszewski, J. J., Qin, J., Gronenborn, A. M. \& Clore, G. M. (1995). The impact of direct refinement against ${ }^{13} \mathrm{C}^{\alpha}$ and ${ }^{13} \mathrm{C}^{\beta}$ chemical shifts on protein structure determination by NMR. J. Magn. Reson. B106, 92-96.

77. Wishart, D. S., Bigam, C. G., Holm, A., Hodges, R. S \& Sykes, B. D. (1995). ${ }^{1} \mathrm{H},{ }^{13} \mathrm{C}$ and ${ }^{15} \mathrm{~N}$ random coil NMR chemical shifts of the common amino acids. I. Investigation of nearest-neighbor effects. J. Biomol. NMR, 5, 67-81.

78. Kuszewski, J. J., Gronenborn, A. M. \& Clore, G. M. (1999). Improving the packing and accuracy of 
NMR structures with a pseudopotential for the radius of gyration. J. Am. Chem. Soc. 121, 2337-2338.

79. Lefèvre, J.-F., Dayie, K. T., Peng, J. W. \& Wagner, G. (1996). Internal mobility in the partially folded DNA binding and dimerization domains of GAL4: NMR analysis of the N-H spectral density functions. Biochemistry, 35, 2674-2686.

80. Bracken, C., Carr, P. A., Cavanagh, J. \& Palmer, A. G. (1999). Temperature dependence of intramolecular dynamics of the basic leucine zipper of GCN4: implications for the entropy of association with DNA. J. Mol. Biol. 285, 2133-2146.

81. Pawley, N. H., Wang, C., Koide, S. \& Nicholson, L. K. (2001). An improved method for distinguishing between anisotropic tumbling and chemical exchange in analysis of ${ }^{15} \mathrm{~N}$ relaxation parameters. J. Biomol. NMR, 20, 149-165.

82. Dosset, P., Hus, J.-C., Blackledge, M. \& Marion, D. (2000). Efficient analysis of macromolecular rotational diffusion from heteronuclear relaxation data. J. Biomol. NMR, 16, 23-28.

83. Smith, P. K., Krohn, R. I., Hermanson, G. T., Mallia, A. K., Gartner, F. H., Provenzano, M. D. et al. (1985). Measurement of protein using bicinchoninic acid. Anal. Biochem. 150, 76-85.

84. Laue, T. M., Shah, B. D., Ridgeway, T. M. \& Pelletier, S. L. (1992). Analytical Ultracentrifugation in Biochemistry and Polymer Science, The Royal Society of Chemistry, Cambridge, pp. 90-125.

85. Perkins, S. J. (2001). X-ray and neutron scattering analyses of hydration shells: a molecular interpretation based on sequence predictions and modelling fits. Biophys. Chem. 93, 129-139.

86. Ansevin, A. T., Roark, D. E. \& Yphantis, D. A. (1970). Improved ultracentrifuge cells for high-speed sedimentation equilibrium studies with interference optics. Anal. Biochem. 34, 237-261.

87. McRorie, D. K. \& Voelker, P. (1993). Self-association Systems in the Analytical Ultracentrifuge, Beckman Instruments, Inc, Fullerton, CA.

88. Laue, T. M. \& Stafford, W. F. (1999). Modern appli- cations of analytical ultracentrifugation. Annu. Rev. Biophys. Biomol. Struct. 28, 75-100.

89. Schmid, F. X. (1990). Spectral methods of characterizing protein conformation and conformational changes. In Protein Structure: A Practical Approach (Creighton, T. E., ed.), pp. 251-285, IRL Press, Oxford.

90. Mayr, L. M., Landt, O., Hahn, U. \& Schmid, F. X. (1993). Stability and folding kinetics of ribonuclease $\mathrm{T}_{1}$ are strongly altered by the replacement of cis-proline 39 with alanine. J. Mol. Biol. 231, 897-912.

91. Barton, G. J. (1993). ALSCRIPT: a tool to format multiple sequence alignments. Protein Eng. 6, 37-40.

92. Kraulis, P. J. (1991). MOLSCRIPT: a program to produce both detailed and schematic plots of protein structures. J. Appl. Crystallog. 24, 946-950.

93. Merritt, E. A. \& Murphy, M. E. P. (1994). Raster3D Version 2.0. A program for photorealistic molecular graphics. Acta Crystallog. sect. D, 50, 869-873.

94. Nicholls, A., Sharp, K. A. \& Honig, B. (1991). Protein folding and association: insights from the interfacial and thermodynamic properties of hydrocarbons. Proteins: Struct. Funct. Genet. 11, 281-296.

Edited by A. G. Palmer III

(Received 19 September 2003; received in revised form 24 December 2003; accepted 24 December 2003)

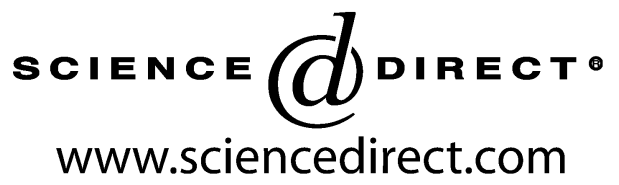

Supplementary Material comprising six Figures and two Tables is available on Science Direct 